\title{
Thermal stability of foils made of graphene-oxide and graphene-oxide with fullerene and their composites with methylcarboxy cellulose and with beta 1,3/1,6 - D - glucan
}

\author{
Klouda Karel ${ }^{1,2}$, Zemanova Eva ${ }^{2}$, Friedrichova Romana ${ }^{3}$, Bradka Stanislav ${ }^{4}$, Gembalova Lucie $^{5}$ \\ ${ }^{1}$ VŠB-Technical University of Ostrava, Faculty of Safety Engineering, Czech \\ ${ }^{2}$ State Office for Nuclear Safety, Prague, Czech \\ ${ }^{3}$ Ministry of the Interior - General Directorate of the Fire Rescue Service of the Czech Republic, Technical Institute of Fire Protection \\ ${ }^{4}$ National Institute for Nuclear, Chemical and Biological Protection, Kamenna, Czech \\ ${ }^{5}$ VŠB-Technical University of Ostrava, Faculty of Mining and Geology, Czech
}

\section{Email address:}

Eva.zemanova@sujb.cz (Z.Eva), Karel.Klouda@sujb.cz (K. Karel)

\section{To cite this article:}

Klouda Karel, Zemanová Eva, Friedrichová Romana, Brádka Stanislav, Gembalová Lucie. Thermal Stability of Foils Made of GrapheneOxide and Graphene-Oxide with Fullerene and their Composites with Methylcarboxy Cellulose and with Beta 1,3/1,6 - D - Glucan. International Journal of Materials Science and Applications. Vol. 3, No. 5, 2014, pp. 226-245. doi: 10.11648/j.ijmsa.20140305.24

\begin{abstract}
This contribution contains data on thermal stability of certain materials whose initial precursor is graphite. Graphite was oxidized separately and in a mixture with fullerene $\mathrm{C}_{60}$. The prepared oxides were processed with vacuum filtration to produce foils and their morphology and thermal stability was described. The graphene oxides reacted with nano-cellulose and B-glucan to produce composites. The prepared composites in the form of foils were tested for thermal stability and further analyzed e.g. by FT-IR, SEM, etc.
\end{abstract}

Keywords: Graphene Oxide, Fullerene - $\mathrm{C}_{60}$, Intercalate, Composite, Nano-Cellulose, B-Glucan

\section{Introduction}

Graphite is an allotropic modification of carbon with $\mathrm{sp}^{2}$ bonds and made up of layers of mutually interconnected hexagonal rings. The layers are arranged in parallel planes $335 \mathrm{pm}$ apart. Carbon atoms in the adjoining layers are not chemically bonded to each other and they are attached by weak van der Waals forces that make it possible for various atoms or molecules in liquid or gaseous form to get in between the carbon layers. The resulting substances are called intercalation compounds of graphite and their characteristic parameter is the so-called "degree of intercalation", which indicates the number of carbon layers between two layers of an intercalated substance (Klouda, 1985).

Depending on a type of the intercalated substance the graphite plane may be either an acceptor or donor of electrons. Another option is the so-called $\pi$-complex created by intercalation of substances of $\mathrm{AX}_{\mathrm{y}}$ type, where $\mathrm{A}$ is a metal or non-metal with a high valence status, $\mathrm{X}$ is an electronegative element and $\mathrm{y}$ is a stoichiometric coefficient.

Intercalates of graphite with alkali metals have been known since 1930s. They are called intercalates of the first degree with the formula $\mathrm{C}_{8} \mathrm{M}(\mathrm{M}=\mathrm{K}, \mathrm{Rb}, \mathrm{Cs})$, i.e. they are characterized by a stacking sequence of layers of carbon and alkali metal.

Intercalates of graphite with alkali metals or in combination with other metals have been used in a number of applications as catalysts, e.g. for synthesis of ammonia, synthesis of carbohydrates by hydrogenation of carbon oxides, hydrogenation of olefins, they have sorption properties etc. (Klouda, 1985). Substituents can be chemically bonded to graphite under certain conditions by fluorination or oxidization.

Fluorination of graphite with elemental fluorine at 400$600^{\circ} \mathrm{C}$ produces a covalent compound called fluorographite $\mathrm{CF}_{\mathrm{x}}, \mathrm{x}=0.25-1.12$, depending on reaction conditions of the 
fluorination (Klouda, 1985). Oxidization of graphite with strong oxidizing agents produces graphene oxide (GO), which is a precursor for chemical preparation of graphene (Makharza et. al., 2013).

Publications dealing with oxidization of graphite to prepare G-O usually specify a method used as described by specific authors: Hoffmann $\left(\mathrm{HNO}_{3}, \mathrm{KClO}_{3}\right)$, Staydennaier $\left(\mathrm{HNO}_{3}, \mathrm{KClO}_{3}\right)$, Tour $\left(\mathrm{P}_{2} \mathrm{O}_{5}, \mathrm{KMnO}_{4}\right)$, Hummers $\left(\mathrm{NaNO}_{3}\right.$, $\mathrm{KMnO}_{4}$ ). In all those methods the main chemical agent used is concentrated sulfuric acid (Chang and Pumera, 2013).

$\mathrm{GO}$ is a compound made up of a carbon skeleton with main functional groups, such as carboxyl, carbonyl, epoxy and ether groups and hydroxy- groups. These functional groups enable chemical reactions of GO (Zang et. al., 2011) to form covalent bonds with other compounds (e.g. esterification, amidation).

Another option is a GO reaction to form non-covalent bonds (Makharza et. al., 2013). The possible types of the bonds are hydrogen bonds, van der Waals forces, $H-\pi$, cation- $\pi$, anion- $\pi, \pi-\pi$, electrostatic forces. These noncovalent bonds are employed in preparation of composite polymers, biopolymers (Yoo, B. M. et. al., 2013) and in use of $\mathrm{GO}$ adsorption and absorption properties (Kyzas et. al., 2014; Fakhri et al., 2013; Chabot et. al., 2014). GO suspension can be vacuum filtered to prepare foils that find use in biology, electrical engineering, optics (Russo et. al., 2013) and biomedicine (Shen et. al., 2012).

Graphene can be prepared by a chemical method which consists in reduction of oxidized carbon (functional groups) in GO with various reducing agents (hydrazine, metal hydride, hydrogen, hydrogen iodide) or reducing methods, such as reflux in a polar solvent, microwaves irradiation, electrochemical reduction (Dreyer et. al., 2010).

The composition of graphene-oxide and its decomposition by an exothermic reaction indicates a potential fire risk. This shall apply mainly to industrial production, processing and storage of GO-materials. If stored in a solid form GO shall be protected against sources of heat, electric discharges and exposure to high-intensity light. A question which appeared in publications by Krishnan et al. (Krishnan et al., 2012), i.e. whether GO is a fire retarder or fire hazardous material, has defined the objective of this work in which we want to assess behavior of $\mathrm{GO}$ and $\mathrm{GO}-\mathrm{C}_{60}$ foils and their composites with cellulose and B-glucan when thermally exposed.

\subsection{Experimental Part}

Employed chemicals:

Graphite PM - very fine crystalline powder graphite, mesh 0.025mm, Supplier: Koh-I-Noor Netolice, Czech Republic

Fullerene $\mathrm{C}_{60}, 99.5 \%$ purity, SES Research, Houston USA

Sulfuric acid, nitric acid, potassium permanganate , sodium hydrocarbonate, CM - cellulose C4146 - Supplier: Sigma-Aldrich
Beta 1,3/1,6 - D - glucan (59\% beta, 9\% alpha), botanic source oyster mushroom, Supplier: Dimenzia s.r.o., Kežmarok Slovakia.

Employed methods:

Ultrasonification with PS4000A, power output 500W, thermostat $0-77^{\circ} \mathrm{C}$, frequency $35 \mathrm{kHz}$

ATR analysis by means of FTIR spectrometry was performed using the spectrometer Brucker Aplha/FT-IR, ART crystal (identified as Platinum Diamond 1 Ref1), software OPUS 6,5, source IR SiC Globar. The number of spectrum scans was 24 , resolution $4 \mathrm{~cm}^{-1}$, spectrum range $375-4000 \mathrm{~cm}^{-1}$.

Thermal analyses TGA and DSC of the prepared nanofibers were performed on STA 1500, Instrument Specialists Incorporated-THASS, analytical scale SUMMIT, SI $234-4$, at flow rate $20 \mathrm{ml} / \mathrm{min}$., heating rate $10^{\circ} \mathrm{C} / \mathrm{min}$., ceramic crucible, diameter $5 \mathrm{~mm}$ and height $8 \mathrm{~mm}$, degradation medium: air.

Morphology of the nanofibers was determined with SEM Phenom FEI and SEM FEI Quanta 650 FEG (USA).

\subsection{Preparation of Graphene-Oxide (GO) and Graphene- Oxide $+C_{60}\left(G O-C_{60}\right)$}

Graphite was oxidized with a mixture of $\mathrm{H}_{2} \mathrm{SO}_{4}, \mathrm{KMnO}_{4}$ and $\mathrm{NaNO}_{3}$ according to Hummers and Offerman (Hummers and Offerman, 1958). Graphite, sulfuric acid and sodium nitrate (for experiments I-II also fullerene $\mathrm{C}_{60}$ ), were placed into a flask, the mixture was stirred and cooled to $10^{\circ} \mathrm{C}$. Potassium permanganate was subsequently added into the reaction mixture through a hopper in small doses. The mixture with the permanganate was slowly heated to $60^{\circ} \mathrm{C}$ and stirred at that temperature for 3 hours. Then it was left to stand for three days at the laboratory temperature.

The obtained product was filtered off, washed with big quantity of distilled water until negative reaction to sulfate anions and dried for three days on a Petri dish at $50-60^{\circ} \mathrm{C}$ to form foils of $\mathrm{GO}$ or $\mathrm{GO}-\mathrm{C}_{60}$.

Samples weights for the individual experiments I -III

I and II : $1 \mathrm{~g}$ graphite PM; $35 \mathrm{ml} \mathrm{H}_{2} \mathrm{SO}_{4} ; 2.11 \mathrm{~g} \mathrm{NaNO}_{3}$; $0.5 \mathrm{~g} \mathrm{C}_{60}$ and $4.6 \mathrm{~g} \mathrm{KMnO}_{4}$

III.: 2 g graphite PM; $45 \mathrm{ml} \mathrm{H}_{2} \mathrm{SO}_{4} ; 2.8 \mathrm{~g} \mathrm{NaNO}_{3}$ and $6.5 \mathrm{~g} \mathrm{KMnO}_{4}$

\subsection{Oxidation of Fullerene Alone $C_{60}$ (Blank Test)}

In order to confirm or to refute our theoretical assumptions about behavior of fullerene in an oxidation mixture we have performed an experiment in which we maintained mutual ratios of carbon to the other reagents as those used in the experiment with graphite $\left(0.7 \mathrm{~g} \mathrm{C}_{60}, 1 \mathrm{~g} \mathrm{NaNO}_{3}, 2 \mathrm{~g} \mathrm{KMnO}_{4}\right.$, $18 \mathrm{ml} \mathrm{H}_{2} \mathrm{SO}_{4}$ ). Also the reaction times and subsequent treatment were equivalent. After vacuum filtration we did not obtain foils but after the drying we obtained black loose powder (hereinafter $\mathrm{C}_{60}$-oxi). The powder was investigated with FT-IR, TGA, DSC analysis and the results were compared with analyses of the initial fullerene. 


\subsection{Reaction of $\mathrm{GO}$ and $\mathrm{GO}-\mathrm{C}_{60}$ Foils with Cellulose in Acid Environment}

GO $(0.3 \mathrm{~g})$ and $\mathrm{GO}-\mathrm{C}_{60}(0.3 \mathrm{~g})$ foils were placed into Erlenmeyer flasks and $10 \mathrm{ml}$ of distilled water was added. Foils changed into suspensions after 3 days of irregular stirring and short-term ultrasonification. Subsequently, cellulose was added into the flasks $(0.65 \mathrm{~g})$ and $8 \mathrm{ml} \mathrm{H}_{2} \mathrm{SO}_{4}$ $(96 \%)$. The reaction was exothermic. The mixture was ultrasonificated in a water bath at $40^{\circ} \mathrm{C}$. Then the flask content was poured into $50 \mathrm{ml}$ of distilled water and neutralized with a solution of sodium hydrocarbonate $\left(\mathrm{NaHCO}_{3}\right)$ until neutral reaction. The product was then vacuum filtered and washed on a filter with ca. $40 \mathrm{ml}$ of distilled water, dried at $50^{\circ} \mathrm{C}$ on a Petri dish on which it formed foils.

\subsection{Reaction of $G O$ with $\beta-G l u c a n$}

Graphene oxide (prepared according to Hummers, 1958) in the form of foils $(0.3 \mathrm{~g})$ was placed into Erlenmeyer flasks with $25 \mathrm{ml}$ of distilled water. No suspension was formed after 48 hours and it was necessary to perform repeated ultrasonification $5 \times 2$ minutes to prepare the suspension. Beta - glucan $(0.45 \mathrm{~g})$ was added into the suspensions and in one of the flasks also $0.7 \mathrm{ml}$ of concentrated $\mathrm{H}_{2} \mathrm{SO}_{4}$ (an exothermic process occurred after

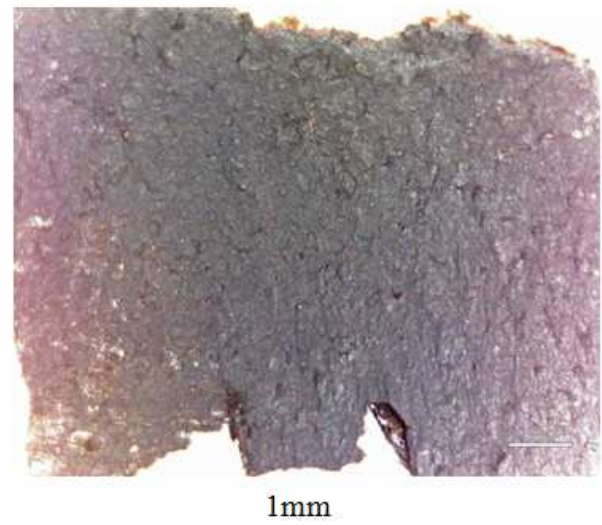

the acid was added).

Visualization of the flask content

- without $\mathrm{H}_{2} \mathrm{SO}_{4}$ gel (product I)

- with $\mathrm{H}_{2} \mathrm{SO}_{4}$ suspension (product II)

Subsequently, Erlenmeyer flasks were placed into a water bath $\left(40^{\circ} \mathrm{C}\right)$ and ultrasonificated 3 times for 2 minutes. Then they were left to stand for 15 days at the laboratory temperature. The flask with the product I (GO$B \mathrm{G})$ was vacuum filtered and the resulting black foil was dried at $50-55^{\circ} \mathrm{C}$. The flask with the product II $\left(\mathrm{GO}-\beta \mathrm{G}, \mathrm{H}^{+}\right)$ was poured into a $300 \mathrm{ml}$ flask, diluted with $200 \mathrm{ml}$ of distilled $\mathrm{H}_{2} \mathrm{O}$ and subsequently 12 times decanted to $\mathrm{pH} 6.5$. The flask contained brown spongy coagulate in $1 / 3$ of the flask volume. A part of the coagulate was vacuum filtered and it formed a brown foil which was dried at $50-55^{\circ} \mathrm{C}$.

\section{Results}

\subsection{Oxidation of Graphite and Mixture of Graphite- $C_{60}$}

The foils obtained by vacuum filtration from the product of oxidation of graphite alone and the product of joint oxidation with $\mathrm{C}_{60}$ had clearly different morphologies (see Fig. 1). $\mathrm{GO}-\mathrm{C}_{60}$ foils looked more compact than $\mathrm{GO}$ foils. When inspecting the morphology with electron microscopy the $\mathrm{GO}-\mathrm{C}_{60}$ foil has a rougher surface (see Fig. 2). For GO$\mathrm{C}_{60}$ foils we also determined its texture.

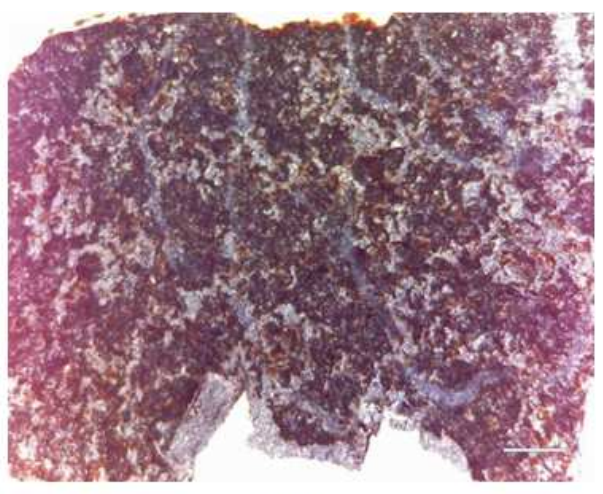

$1 \mathrm{~mm}$

a) foil obtained by oxidation of graphite: front and back side of the foil, scale $1 \mathrm{~mm}$
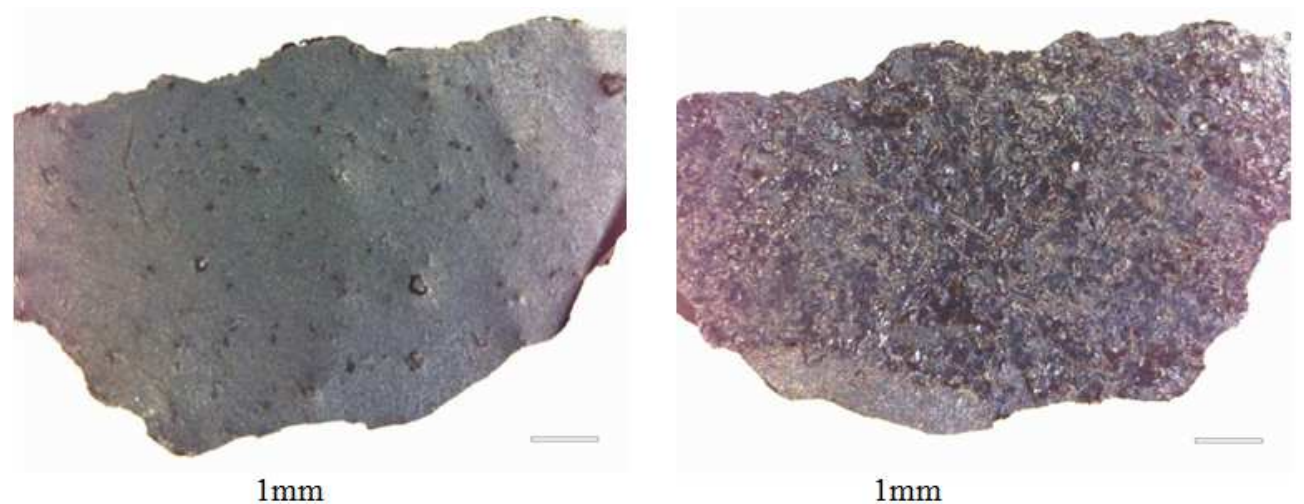

b) foil obtained by oxidation of graphite with fullerene $\mathrm{C}_{60}$ : front and back side of the foil, scale $1 \mathrm{~mm}$

Fig 1. Rough morphology of the foils after vacuum filtration of $G O(a)$ and $G O-C_{60}(b)$ 

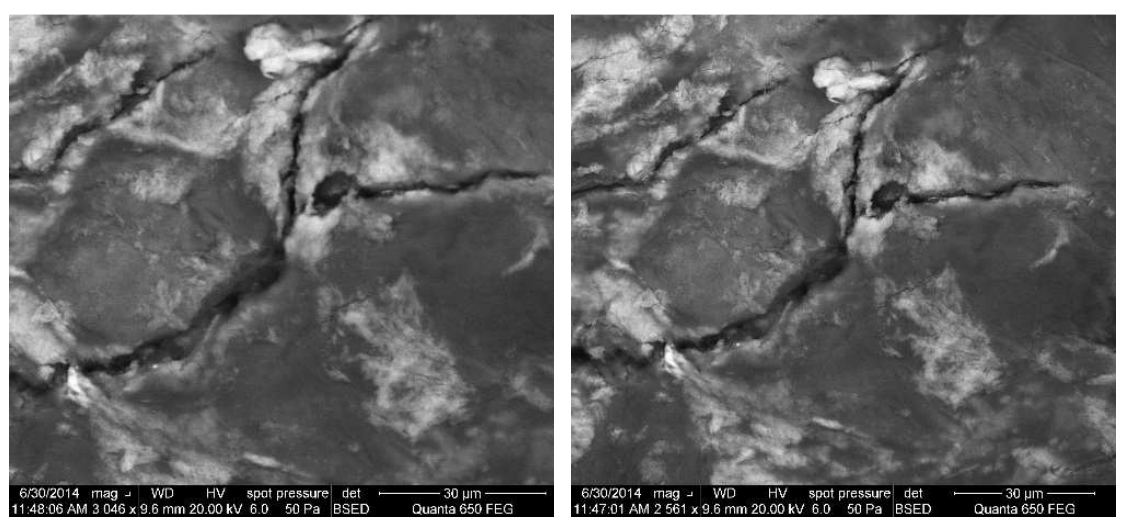

a) GO: different views
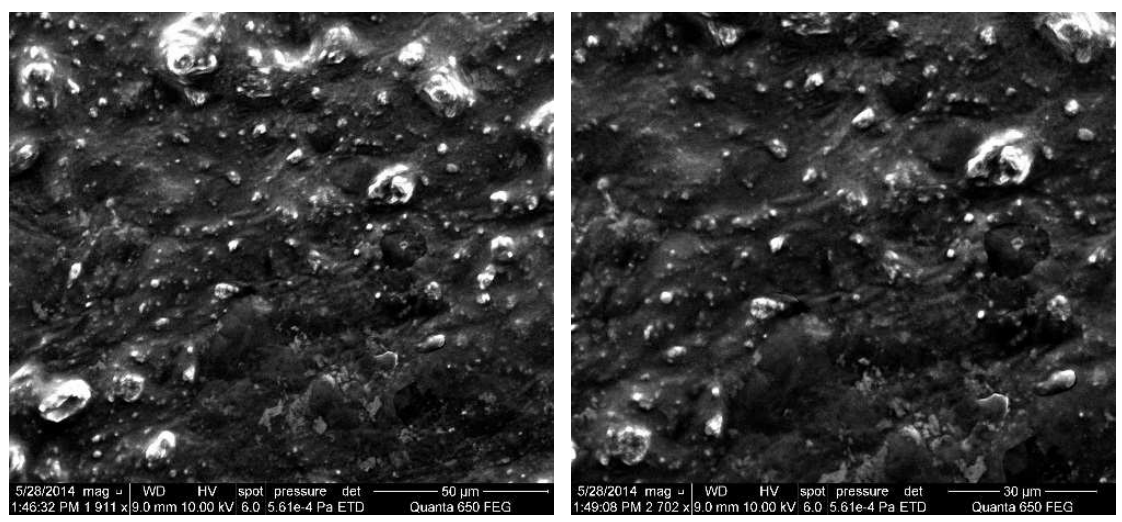

b) GO-C 60 : different views

Fig 2. Fine morphology of the foils after vacuum filtration of $G O$ (a) and $G O-C_{60}(b)$

The specific surface of the foil samples $\mathrm{GO}-\mathrm{C}_{60}$ was 21.9 $\mathrm{m}^{2} / \mathrm{g}$ and the volume of adsorbed monomolecular layer was $5.03 \mathrm{ml} / \mathrm{g}$. The volume of mesopores or macropores was $0.286 \mathrm{ml} / \mathrm{g}$ in comparison with the volume of micropores which was $0.001 \mathrm{ml} / \mathrm{g}$. The volume representation of mesopores was ca. 286 times higher than that of micropores. The sample had a mesoporous character with some representation of macropores. The sample contained very little micropores (see the volume representation - only $0.001 \mathrm{ml} / \mathrm{g}$ ) consisting of the pores with the diameter $0-1$ nm (ca. 63\%) - only one fraction of the pores, while no other micropore fractions were identified - they were probably clogged. The mesopores included the following fractions: $1.5-3 \mathrm{~nm}$ (ca. 38\%), 3-5 nm ( ca. 13\%) and 5-10 $\mathrm{nm}(\mathrm{ca} .5 \%)$ and $10-50 \mathrm{~nm}$ (ca. 8\%). As for macropores, the sample contained only one fraction, while ca. $24 \%$ of the specific surface was formed by macropores with the diameter 50-200 $\mathrm{nm}$. The measured parameters are shown in Table No. 1.

Tab 1. Texture parameters of $G O-C_{60}$ samples

\begin{tabular}{llllll}
\hline $\begin{array}{l}\text { Sample } \\
\text { identification }\end{array}$ & $\mathbf{a}\left[\mathbf{m}^{2} / \mathbf{g}\right]$ & $\mathbf{B}\left[\mathbf{c m}^{3} / \mathbf{g}\right]$ & $\mathbf{c}\left[\mathbf{c m}^{3} / \mathbf{g}\right]$ & $\mathbf{d}\left[\mathbf{c m}^{3} / \mathbf{g}\right]$ & $\mathbf{e}\left[\mathbf{c m}^{3} / \mathbf{g}\right]$ \\
\hline$G O-C_{60}$ & 21.9 & 5.03 & 0.040 & 0.001 & 0.286 \\
\hline
\end{tabular}

$\mathrm{a}$ - specific surface, b - volume of adsorbed monomolecular layer, c cumulative volume of pores, $\mathrm{d}$ - cumulative volume of micropores, e cumulative volume of meso- and macropores
Subsequently, the foils were examined with X-ray analysis (Fig. 3), FT-IR, TGA and DSC analyses. The X-ray analysis has proved a negligible difference in expansion of the space between the layers, see Fig. 3.

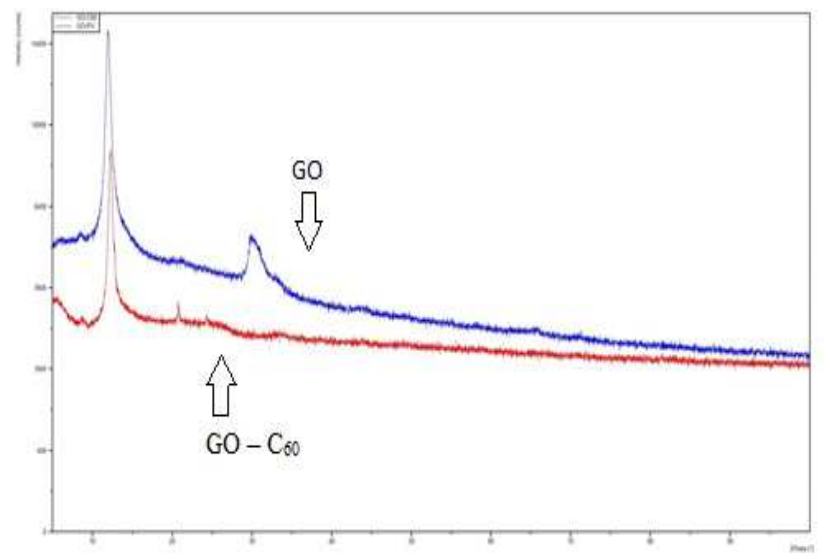

Fig 3. X-ray analysis, GO: $d=739 \mathrm{pm}, 299 \mathrm{pm} ; G O-C_{60}: d=718 \mathrm{pm}, 425$ pm

\subsection{IR Spectrometry of $G O$ and $G O-C_{60}$}




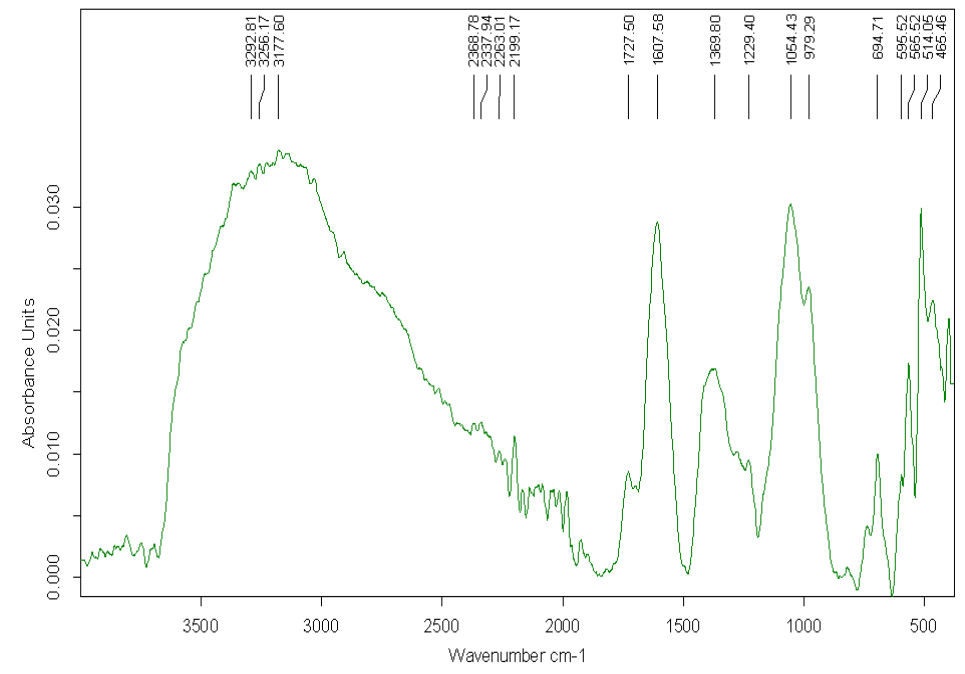

a) GO

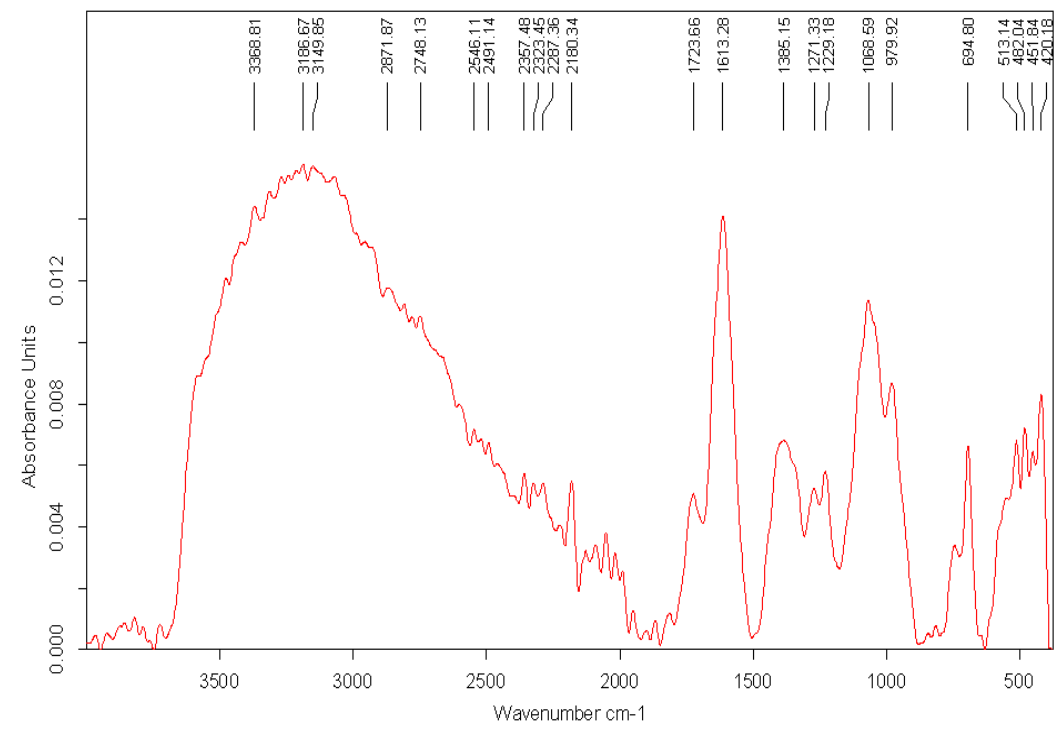

b) $\mathrm{GO}-\mathrm{C}_{60}$

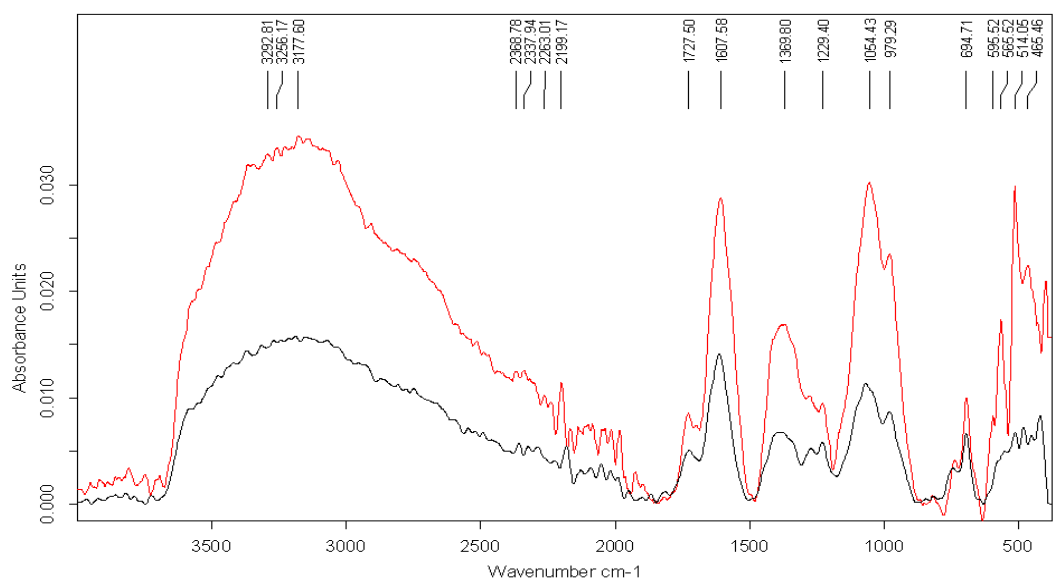

c) $\mathrm{GO}$ and $\mathrm{GO}-\mathrm{C}_{60}$

Fig 4. IR spectrum of products of oxidation of graphite and graphite with $\left.\left.C_{60}: a\right) G O, b\right) G O-C_{60}, c$ ) comparison of the spectrums a) and b) 
When preparing GO by oxidation methods FT-IR is usually indicated as a method for identification of the basic functional groups. In most cases the authors indicate vibration ranges for the given groups:

$$
\begin{aligned}
& 3000-3700 \mathrm{~cm}^{-1} v\left(-\mathrm{COOH},-\mathrm{OH}, \mathrm{H}_{2} \mathrm{O}\right) \\
& 1850-1750 \mathrm{~cm}^{-1} v(-\mathrm{C}=\mathrm{O}) \\
& 1650-1750 \mathrm{~cm}^{-1} v(\text { carboxy } \mathrm{COOH}) \\
& 1500-1600 \mathrm{~cm}^{-1} v\left(\mathrm{sp}^{2} \mathrm{C}=\mathrm{C}\right) \\
& 1280-1320 \mathrm{~cm}^{-1} v \text { (epoxides C-O-C) }
\end{aligned}
$$

At the same time, ranges that follow may contain the following vibrations:

$1280-1500 \mathrm{~cm}^{-1}$ : ethers, epoxides, ketones, peroxides, benzoquinone

$1100-1280 \mathrm{~cm}^{-1}$ : peroxides, ethers, ketones, lactones, anhydrides, epoxides, benzoquinones

$900-1100 \mathrm{~cm}^{-1}$ : lactones, peroxides, hydroxyls, 1,3 dioxane, anhydrides, epoxides, carboxyles -OH bond vibration at $3420 \mathrm{~cm}^{-1}, \mathrm{C}=\mathrm{O}$ bond vibration at $1720-1740$ $\mathrm{cm}^{-1}$.

The mutual comparison of spectrums we obtained for $\mathrm{GO}$ and $\mathrm{GO}-\mathrm{C}_{60}$ is shown in Fig. 4

The difference between the GO and GO- $\mathrm{C}_{60}$ spectrums is in the ratio of the mutual adsorbances for the vibrations:

$\begin{array}{llll}\text { GO } & 1390 & 1274 & 1228 \mathrm{~cm}^{-1} \\ \text { GO-C } & 1378 & 1278 & 1228 \mathrm{~cm}^{-1}\end{array}$

In the spectrum range $700-450 \mathrm{~cm}^{-1}$ the adsorbance of GO has a medium value while for $\mathrm{GO}-\mathrm{C}_{60}$ it is high; in general, $\mathrm{GO}-\mathrm{C}_{60}$ demonstrates higher adsorbances throughout the entire spectrum range.

\subsection{Thermal Tests of $G O$ and $G O-C_{60}$ foils}

Two prominent peaks were detected for samples of GO and $\mathrm{GO}-\mathrm{C}_{60}$ foils on the DSC curve (Fig. 5) which corresponded to exothermic processes. The first exothermic process was accompanied by a substantial drop of weight: for $\mathrm{GO}$ by $43.6 \%$ and for $\mathrm{GO}-\mathrm{C}_{60}$ it was even higher - $51.1 \%$ (see Tab. 2).

In the case of $\mathrm{GO}$ the first exothermic process occurred at $190.9^{\circ} \mathrm{C}$ with the maximum at $225^{\circ} \mathrm{C}$ and thermal effect of $508.4 \mathrm{~kJ} / \mathrm{kg}$; in the case of GO- $\mathrm{C}_{60}$ the process started earlier, at $182.6^{\circ} \mathrm{C}$ with the maximum at $205^{\circ} \mathrm{C}$ and the thermal effect was lower than for GO. The values of thermal effects in the individual temperature intervals are provided in Tab. 3. The second exothermic effect in the case of $\mathrm{GO}$ has its maximum at $450^{\circ} \mathrm{C}$, while for $\mathrm{GO}-\mathrm{C}_{60}$ it was already at $390^{\circ} \mathrm{C}$ and the detailed shape of the curve was different (compare Figures 5 and 6). For $\mathrm{GO}_{-} \mathrm{C}_{60}$ the weight loss during the second exothermic effect was lower than during the exothermic effect in the case of GO, which means a situation different from the first effect.

The weight losses until the first exothermic process are essentially the same for both the foils (ca. 20\%) with mild endothermic effects, with a higher thermal effect for GO (anticipated dehydration). Also the overall thermal effect of decomposition is higher for $\mathrm{GO}-\mathrm{C}_{60}$ foil by ca. $30 \%$ (see Tab. 3).

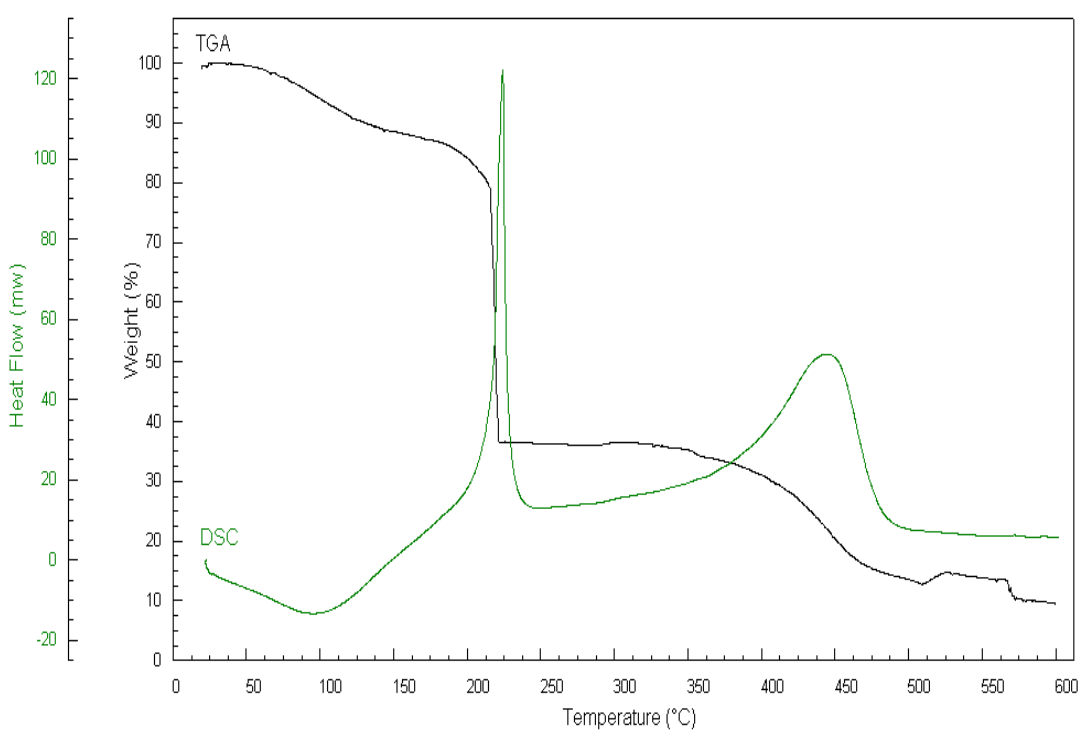

Fig 5. Thermal analysis of a product of graphite oxidation - foil

(degradation medium: air, air flow : $20 \mathrm{ml} / \mathrm{min}$, temperature interval: $25-600^{\circ} \mathrm{C}$, heating rate $10^{\circ} / \mathrm{min}$, sample weight $10.0 \mathrm{mg})$ 


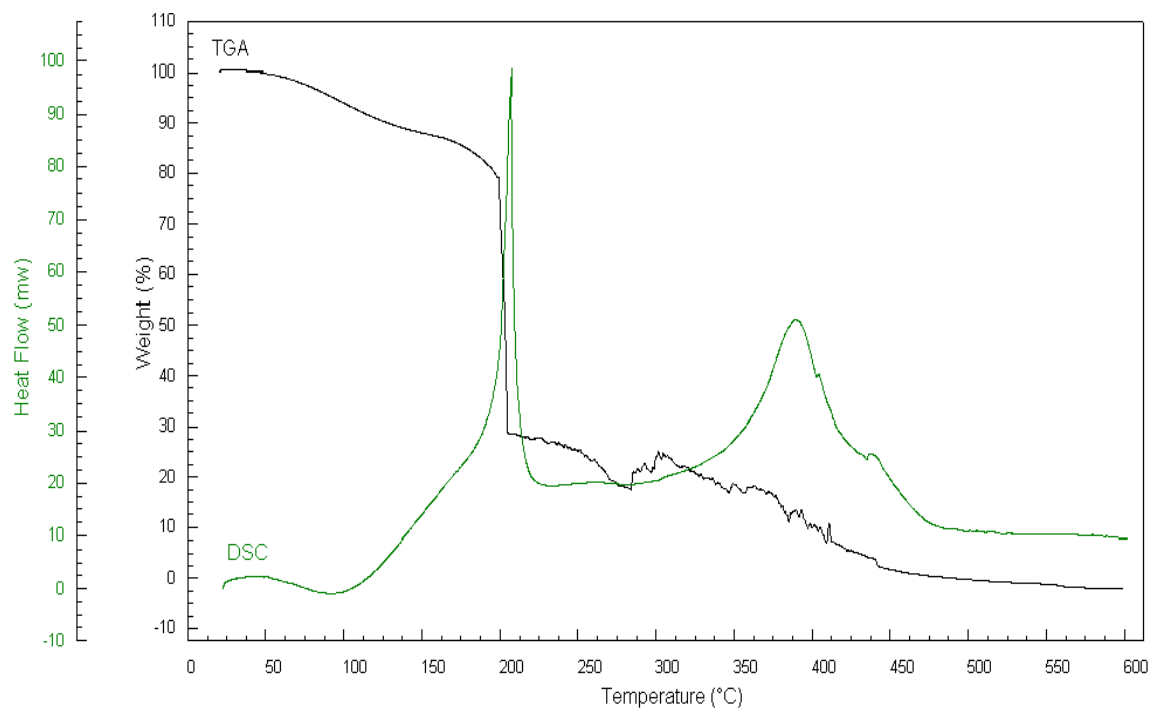

Fig 6. Thermal analysis of a product of graphite and fullerene oxidation-foils

(degradation medium: air, air flow: $20 \mathrm{ml} / \mathrm{min}$, temperature interval: $25-600^{\circ} \mathrm{C}$, heating rate $10 \% \mathrm{~min}$, sample weight $10.0 \mathrm{mg}$ )

When performing the experiments we had some expectations about the course and results of the reaction. The functional groups expected on GO were the following: carboxyl, carbonyl, epoxide, hydroxyl and partly also lactone or sulfonic group. Fullerene $\mathrm{C}_{60}$ was expected to have the following groups on its molecule : $-\mathrm{SO}_{3} \mathrm{H},-\mathrm{OH}$, $\mathrm{NO}_{2},-\mathrm{ONO}_{2}$, epoxide group. Covalent bonds may form between those groups (esterification, dehydration, addition), as well as non-covalent ones - hydrogen bonds, $\pi-\pi$ interaction, van der Waals forces. Also intercalation of a fullerene molecule may occur in the graphene-oxide space. Even breakage of a fullerene molecule in the conditions of oxidation cannot be excluded.

Tab 2. Division of the TGA curve into temperature intervals

\begin{tabular}{llll}
\hline Sample No. & Interval No. & Temperature range $\left({ }^{\circ} \mathbf{C}\right)$ & Weight loss $(\%)$ \\
\hline & 1 & $25.0-142.4$ & 11.0 \\
& 2 & $142.4-213.5$ & 8.8 \\
GO foils & 3 & $213.5-222.3$ & 43.6 \\
& 4 & $222.3-368.8$ & 2.8 \\
& 5 & $368.8-473.0$ & 18.1 \\
& 6 & $473.0-600.0$ & 6.1 \\
& 1 & $25.0-87.1$ & 4.4 \\
& 2 & $87.1-153.0$ & 8.2 \\
GO-C $_{60}$ foils & 3 & $153.0-197.0$ & 8.0 \\
& 4 & $197.0-205.0$ & 51.1 \\
& 5 & $205.0-281.3$ & 10.8 \\
& 6 & $281.3-490.9$ & 18.0 \\
\hline
\end{tabular}

Tab 3. Parameters of the ongoing thermal processes (DSC)

\begin{tabular}{|c|c|c|c|c|c|}
\hline Sample No. & Thermal process No. & Temperature range $\left({ }^{\circ} \mathrm{C}\right)$ & $\Delta \mathbf{H}(\mathbf{k J} / \mathbf{k g}) *$ & $\mathbf{H}_{\mathrm{f} 1}(\mathbf{m W})$ & $\Sigma \Delta H(\mathbf{k j} / \mathbf{k g})$ \\
\hline \multirow{3}{*}{ GO foils } & 1 & $25.0-154.1$ & 874.6 & 15.8 & \multirow{3}{*}{-910.6} \\
\hline & 2 & $190.9-241.1$ & -508.4 & 107.4 & \\
\hline & 3 & $356.5-492.1$ & -1277.1 & 31.0 & \\
\hline \multirow{3}{*}{ GO- $\mathrm{C}_{60}$ foils } & 1 & $42.0-124.2$ & 141.7 & 6.4 & \multirow{3}{*}{-1204.1} \\
\hline & 2 & $182.6-221.5$ & -308.7 & 71.1 & \\
\hline & 3 & $319.7-481.6$ & -1037.1 & 28.1 & \\
\hline
\end{tabular}

$* \Delta \mathrm{H}=$ thermal effect of the process based on the DSC curves

$(\Delta \mathrm{H}>0 \ldots$ endothermic process, $\Delta \mathrm{H}<0 \ldots$ exothermic process $)$ 
One quoted work (Trzaskowski et al., 2013) deals with energy options of a combination of graphene with $\mathrm{C}_{60}$ on the condition that graphene surface is either defect-free or with defects. Chemical attachment of $\mathrm{C}_{60}$ on a monolayer of graphene is not possible for energy reasons. However, in presence of various defects on the graphene C- layer, such as e.g. formation of 4- and 5- atomic rings, Stone-Wales defect and other types of defects (e.g. flower defect, octa-, penta-, hepta- disrupted cyclic formations) may provide space or reactive points for potential bonds with fullerene

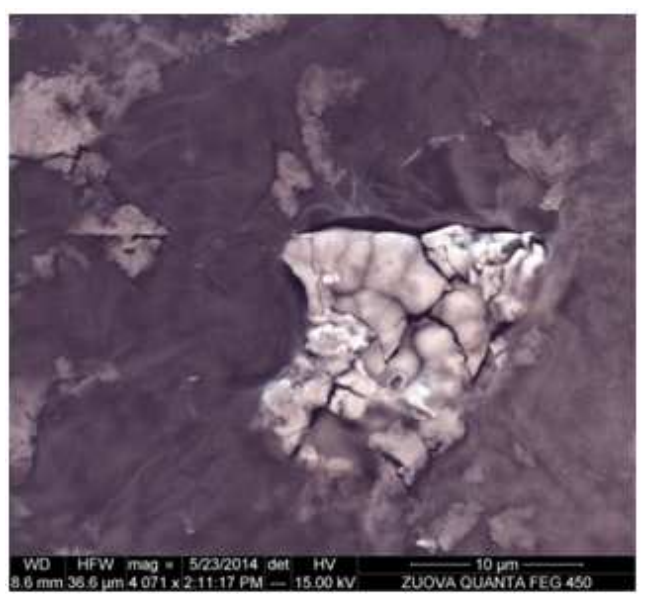

Selected Area 3

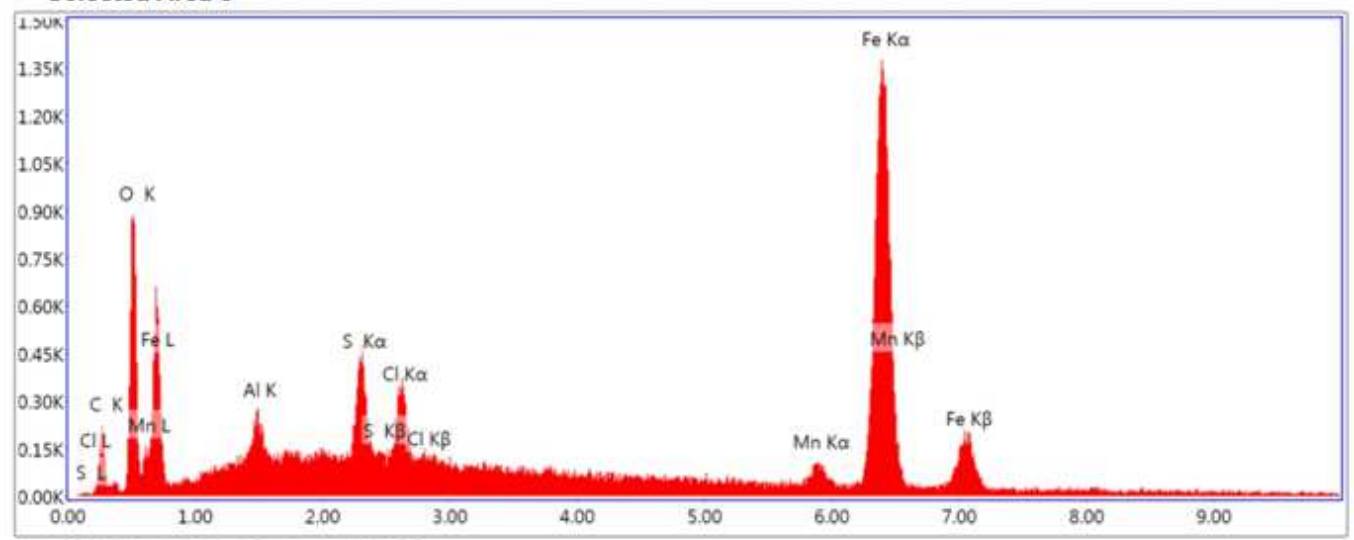

Lsec 20,00 Cnts $0.000 \mathrm{keV}$ Det: Apollo X-SDD Det

Fig 7. Identification of a partly oxidized adatom of $\mathrm{Fe}$

We performed the so-called blank test to get some notion of how fullerene behaves in the oxidizing environment to which it is exposed jointly with graphite.

\subsection{FT-IR Analysis of $C_{60^{-}}$Oxi and Initial $C_{60}$}

The measured IR spectrum of the initial fullerene $\mathrm{C}_{60}$ is provided in Fig. 8. The main characteristic vibrations for $\mathrm{C}_{60}$ (Saeedfar et al., 2013) are $522 \mathrm{~cm}^{-1}, 573 \mathrm{~cm}^{-1}, 1159 \mathrm{~cm}^{-}$ 1 , and $1426 \mathrm{~cm}^{-1}$ and they are also a part of the $\mathrm{C}_{60}$-oxi spectrum.

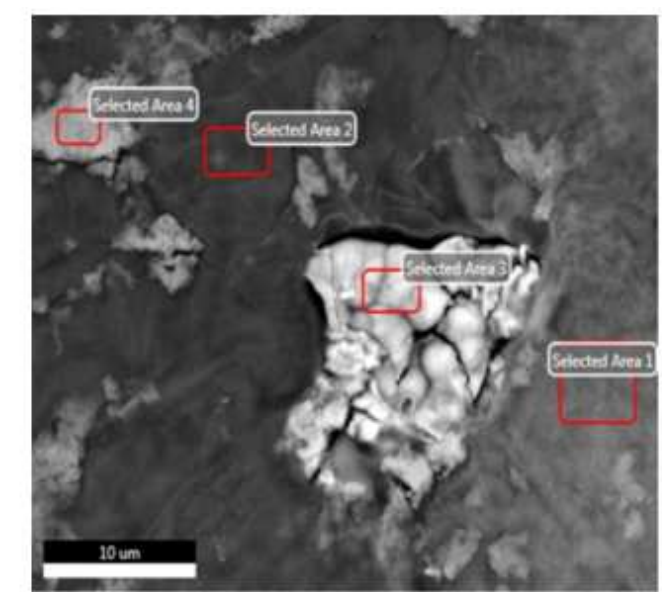

$\mathrm{C}_{60}$.

One of the defects mentioned for the graphene structure is the so-called "adatom" - an adsorbed atom. It is a defect in which e.g. transition metal is adsorbed on the $\mathrm{C}$ lattice. Adsorption of transition metals changes physicochemical properties and biocompatibility of graphene or GO (Faye, 2012; Neto, 2009). We have identified a similar defect in the prepared GO: it was e.g. an atom of Fe identified by EDAX in the GO structure (Fig. 7).

For $\mathrm{C}_{60}$-oxi (Fig. 9) we have identified an additional weak vibration in the absorption interval 1556-1644 $\mathrm{cm}^{-1}$ (probably $\mathrm{C}=\mathrm{C}, \mathrm{C}=\mathrm{O}$ ), $1000-1100 \mathrm{~cm}^{-1}$ (probably C-O-C epoxy, alkoxy, C-CO-C) and a medium vibration at $702 \mathrm{~cm}^{-}$ 1 (probably a substituted aromatic ring). Based on characteristic vibrations of functional groups we can probably exclude presence of the following functional groups on the $\mathrm{C}_{60}$-oxi molecule: $-\mathrm{OH},-\mathrm{COOH},-\mathrm{COOR}$, $\mathrm{SO}_{3} \mathrm{H},-\mathrm{NO}_{\mathrm{x}}$. 


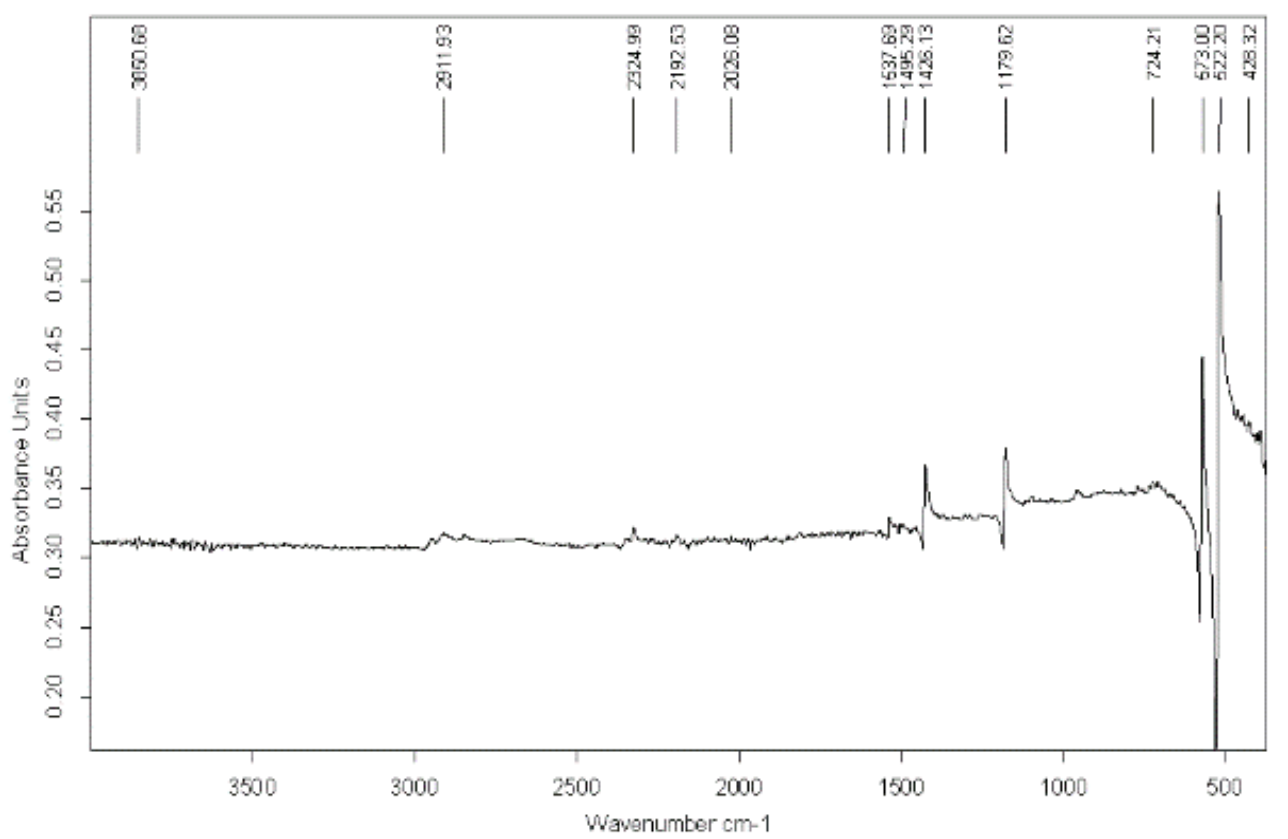

Fig 8. IR-spectrum of $C_{60}$

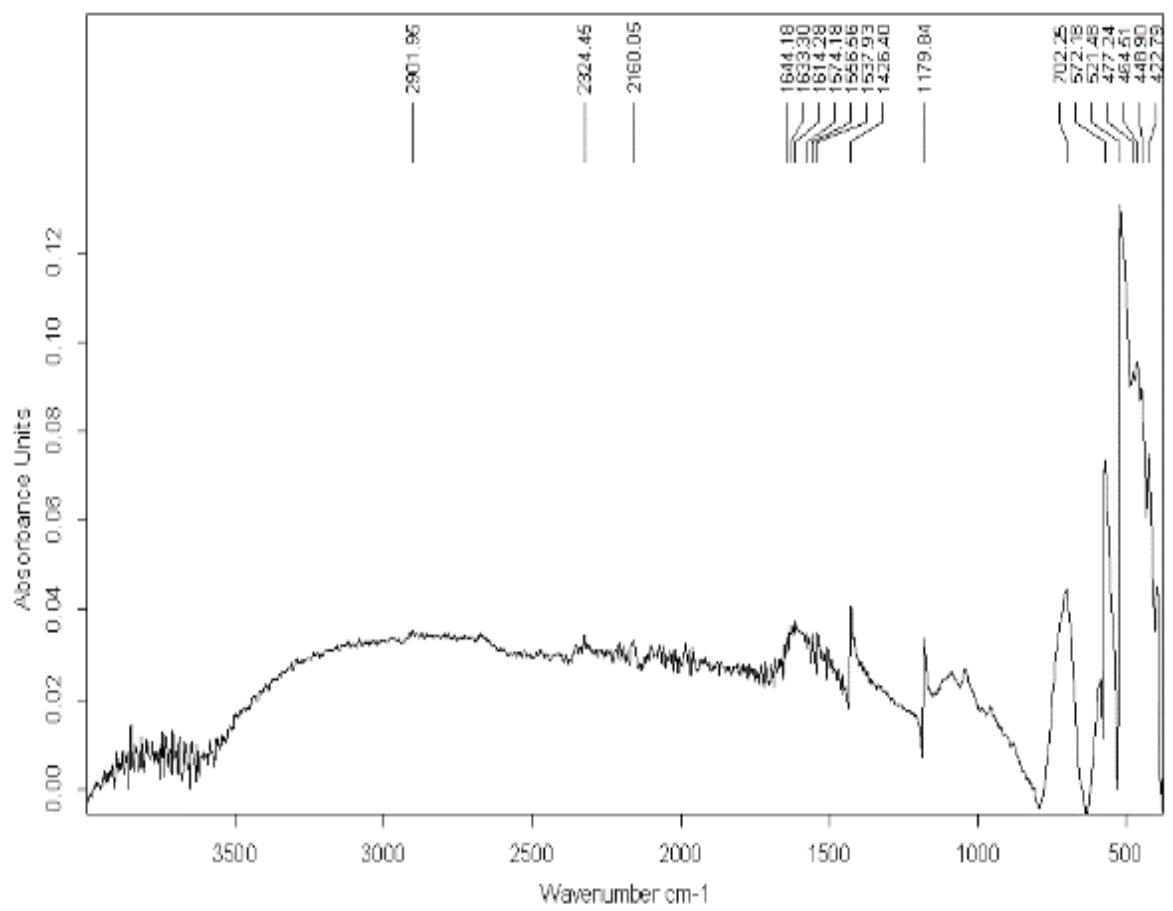

Fig 9. IR-spectrum of $C_{60}$-oxi

\subsection{Thermal Stability of $C_{60^{-}}$Oxi and Initial $C_{60}$}

In the measured temperature range, as indicated by the TGA and DSC curves (Fig. 10-11) up to ca. $420^{\circ} \mathrm{C}$, there were no thermal effects on either of the tested samples and the weight loss of both the samples was comparable in units of percents $\left(6.1 \%\right.$ for $\mathrm{C}_{60}$ and $8.6 \%$ for $\mathrm{C}_{60}$-oxi). In the temperature range of $420-600^{\circ} \mathrm{C}$ both the samples underwent exothermic reactions, however the thermal effects were very different. The thermal effect of $\mathrm{C}_{60}$-oxi was 20 times higher than that of the initial $\mathrm{C}_{60}(1947 \mathrm{~kJ} / \mathrm{kg}$ for $\mathrm{C}_{60^{-}} \mathrm{oxi}$ and $180 \mathrm{~kJ} / \mathrm{kg}$ for $\mathrm{C}_{60}$ ). The weight loss of $\mathrm{C}_{60^{-}}$ oxi $(56.7 \%)$ was twice bigger than that of $\mathrm{C}_{60}(28.8 \%)$. 


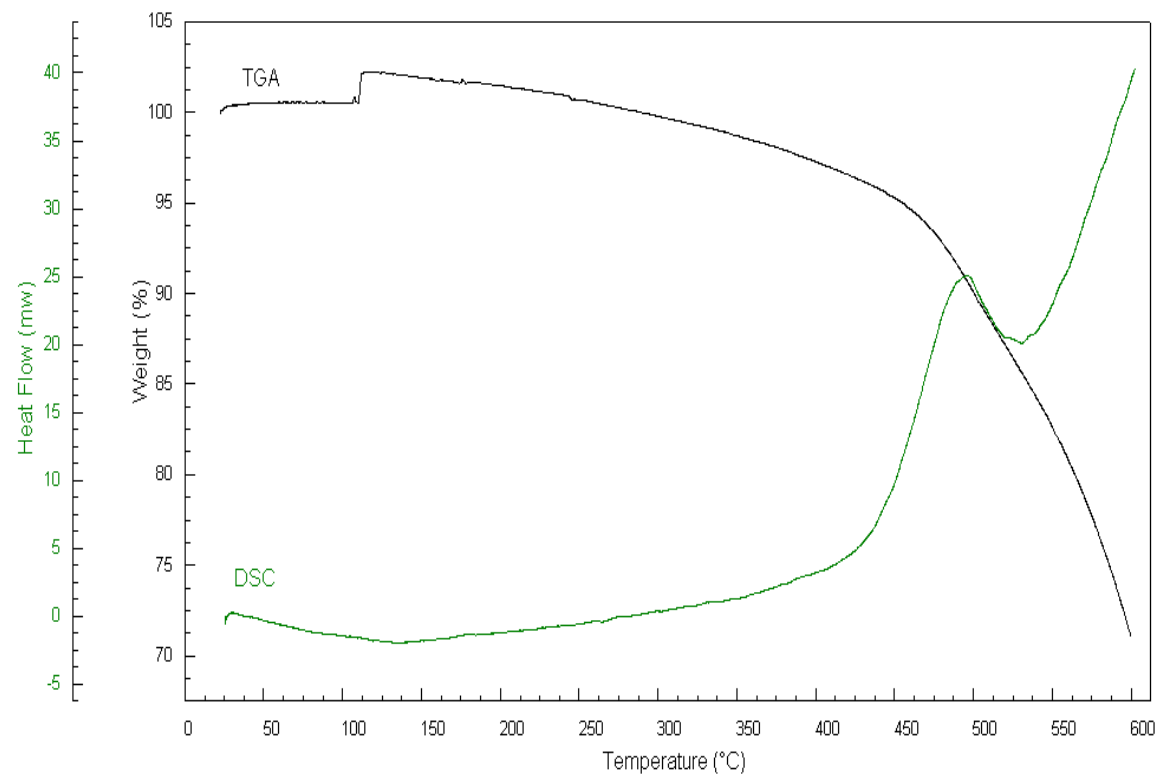

Fig 10. Thermal analysis of C60 (degradation medium: air, air flow $20 \mathrm{ml} / \mathrm{min}$, temperature interval $25-600^{\circ} \mathrm{C}$, heating rate $10^{\circ} / \mathrm{min}$, sample weight 11.21 $m g)$.

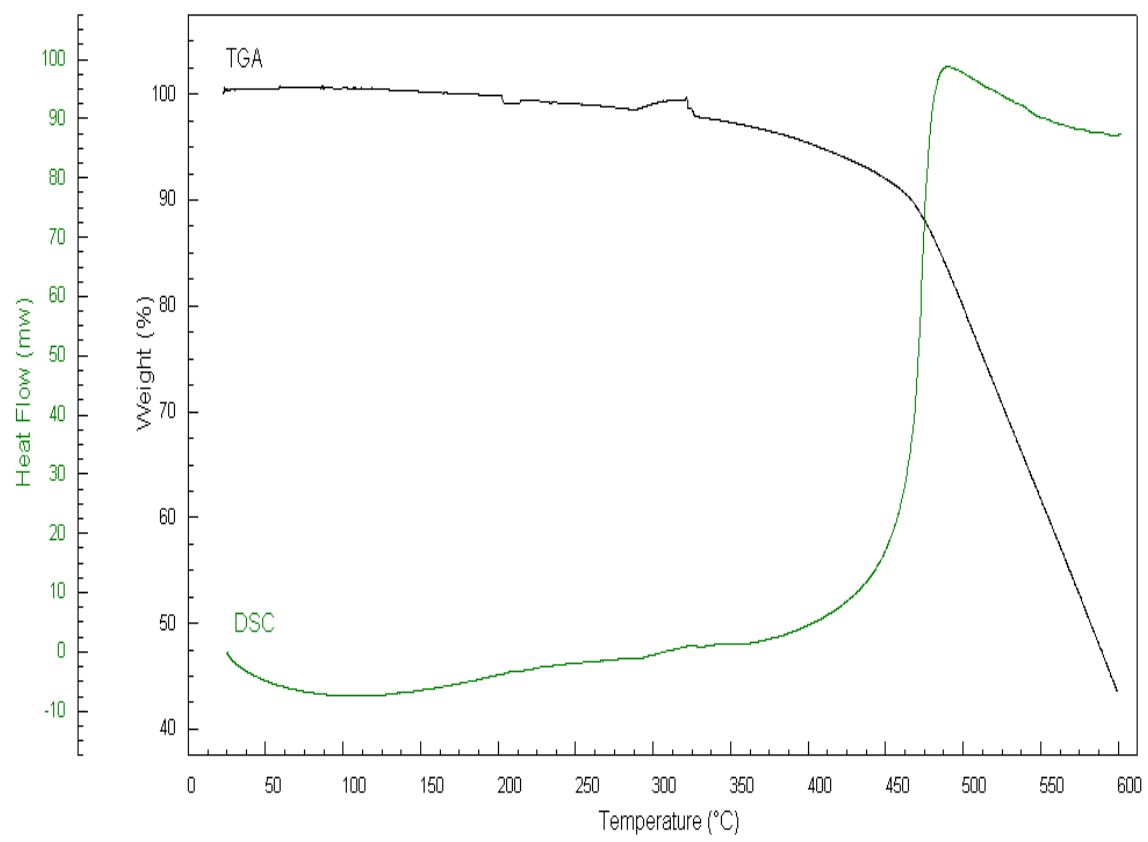

Fig 11. Thermal analysis of C60-oxi (degradation medium: air, air flow $20 \mathrm{ml} / \mathrm{min}$, temperature interval $25-600^{\circ} \mathrm{C}$, heating rate $10^{\circ} /$ min, sample weight $11.56 \mathrm{mg}$ ).

The resistance of $\mathrm{C}_{60}$-oxi against thermal exposure was partly disrupted. We anticipate partial oxidation of the Cskeleton (IR-spectrum Fig. 9) and thus disruption of its consistence (electron balance) which means that defects can appear in the carbon structure when the material is heated - e.g. the Stone-Wales defect (Kabir et al., 2011).

We have identified a similar reduction of resistance of the fullerene carbon skeleton in its bromo-derivative. After endothermic disruption of $\mathrm{C}-\mathrm{Br}$ bond the $\mathrm{C}_{60}$ molecule fully $(100 \%)$ decomposed at $420-550^{\circ} \mathrm{C}$.

We are fully aware of the fact that this so-called "blind test" may not completely correspond to the oxidation process in presence of graphite or graphene-oxide in which a carbo-catalytic effect may apply (Navalon et al., 2014; Su and Loh, 2013).

\subsection{Reaction $\mathrm{GO}$ and $\mathrm{GO}-\mathrm{C}_{60}$ with Cellulose}

Nanocellulose - nanowhiskers - can be prepared by hydrolysis of cellulose polymer (Bodeson et al., 2006). Optimum conditions for the preparation depend on concentration of the employed acid $\left(\mathrm{H}_{2} \mathrm{SO}_{4}, \mathrm{HCl}\right)$, ratio of cellulose and acid, time of hydrolysis and on reaction temperature. Naturally, the result is also influenced by the type of the initial cellulose which can come from hard or 
soft wood, bamboo, sisal, cotton etc. All those factors influence yield and size of the prepared cellulose nanofibers (Ioelovich, 2012; Li and Rageuskas, 2011). The prepared nanocrystalline cellulose can be chemically modified, e.g. esterifed, carboxylated or oxidized (Peng et al., 2011). It may be also used as a composite in polymers or as a matrix for metal nanoparticles.

In our case we performed hydrolysis of methylcarboxy cellulose in presence of suspensions of GO and GO- $\mathrm{C}_{60}$. We assumed that mutual interconnection may occur by a chemical reaction (e.g. esterification, interconnection with

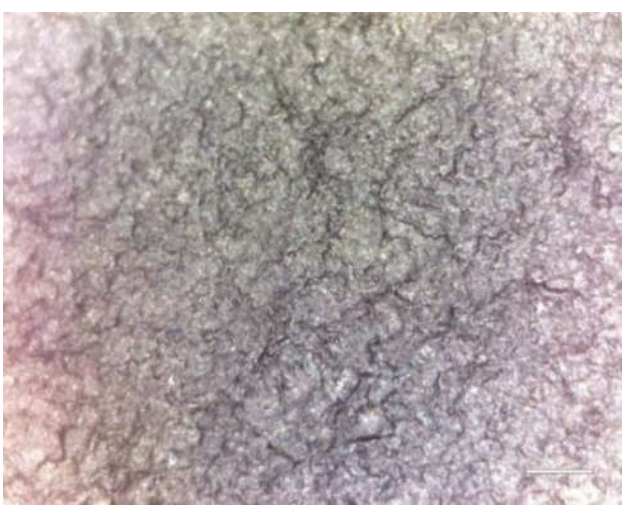

a)
C-O-C bond etc.) or physicochemical bond (e.g. hydrogen bonds). The foils prepared by vacuum filtration of the reaction product were subject to microscopic surface analysis, FT-IR, TGA and DSC analysis.

Morphology of the surfaces as shown by microscopic analysis (see Fig. 12) was different and it suggested a potential method of interconnection between $\mathrm{GO} / \mathrm{GO}-\mathrm{C}_{60}$ and nanocellulose. The detailed morphology (electron microscope) of the prepared composite foils is shown in Fig. 13 and 14.

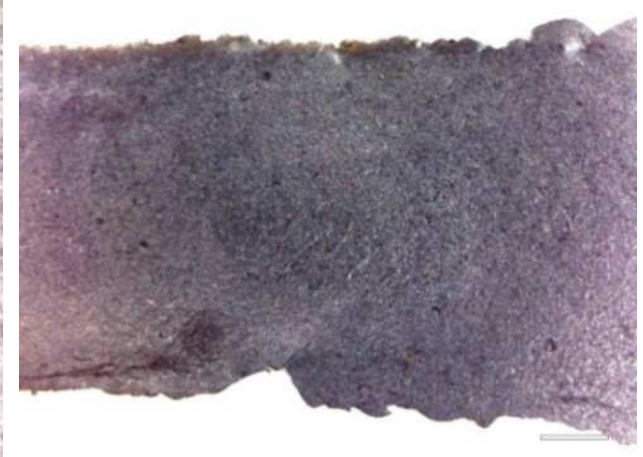

b)

Fig 12. Rough morphology of the foil surfaces after the mutual reaction of $G O-C_{60}(a)$ and $G O$ (b) with cellulose
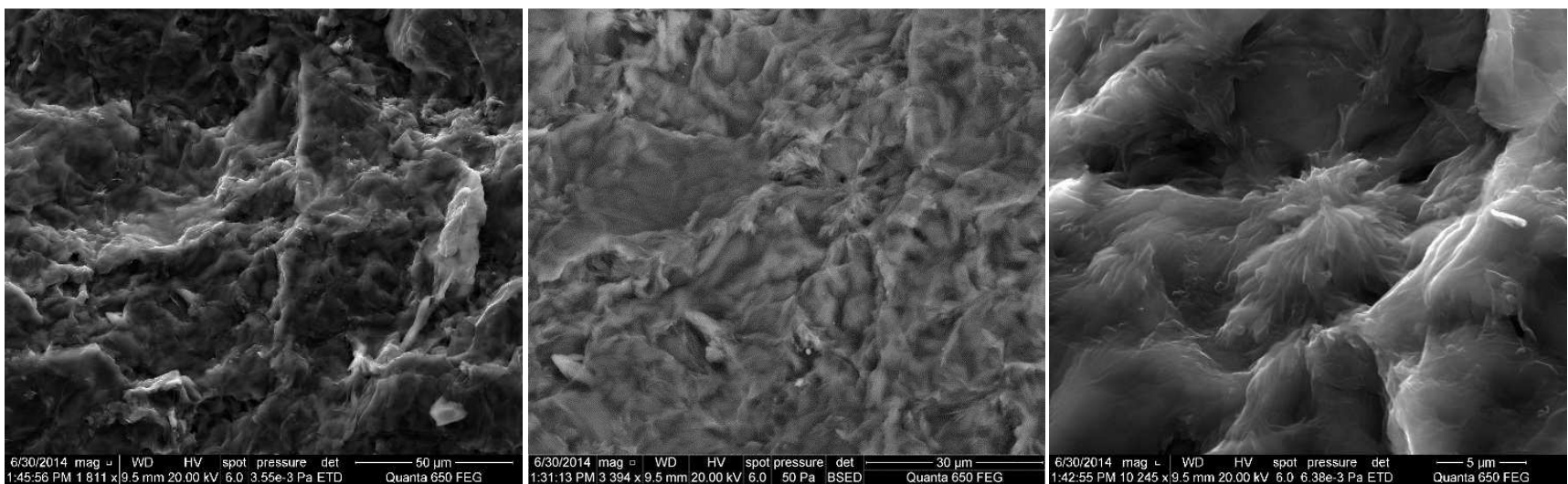

Fig 13. SEM of GO-C $C_{60}$ foils with cellulose: scale $5 \mu \mathrm{m}, 30 \mu \mathrm{m}$ and $50 \mu \mathrm{m}$
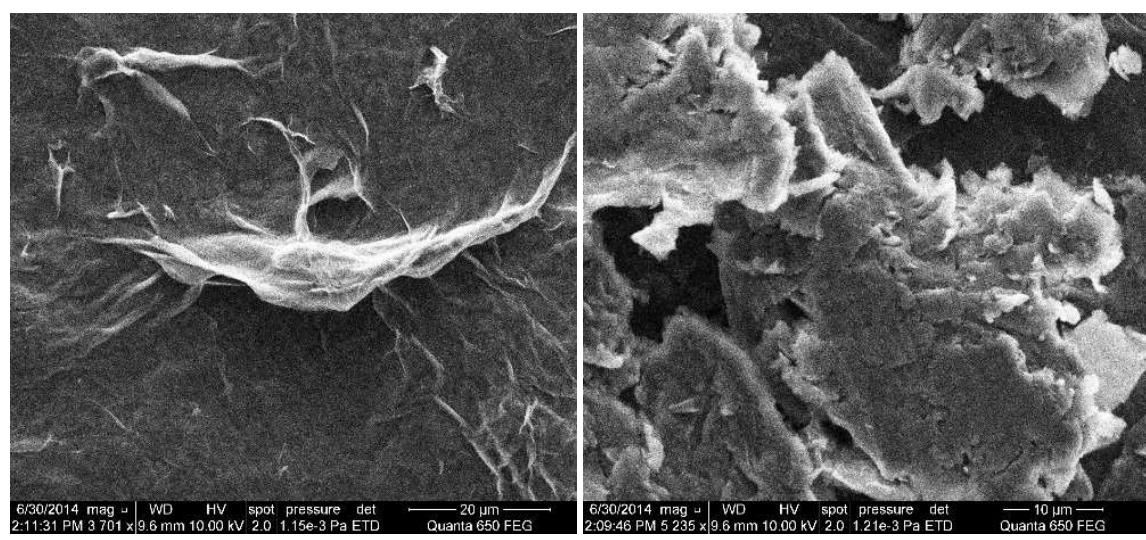

Fig 14. SEM of GO-cellulose foils: scale $10 \mu \mathrm{m}$ and $20 \mu \mathrm{m}$ 


\subsection{FT-IR Analysis of a Product of GO and GO 60 Reaction with Cellulose (Nanocellulose)}

We assume that in the first case the cellulose hydrolysis was only partial and whiskers of nanocellulose generated after the hydrolysis were of bigger size. At the same time, there was no reaction of $\mathrm{C}=\mathrm{O}$ groups, unlike in the case of $\mathrm{GO}$, where IR analysis of the product of reaction with cellulose identified no vibration at $1722 \mathrm{~cm}^{-1}$, which was present in the spectrum of the original GO. The other vibrations characterizing the groups $\mathrm{C}-\mathrm{O}, \mathrm{C}=\mathrm{C}, \mathrm{C}-\mathrm{O}$ and $\mathrm{C}$ $\mathrm{O}-\mathrm{C}$ shifted their frequencies and also the mutual absorption ratios were different (Fig. 15).

The same applies in respect to the initial GO, GO-C 60 and cellulose (compare with the spectrums in Fig. 4)

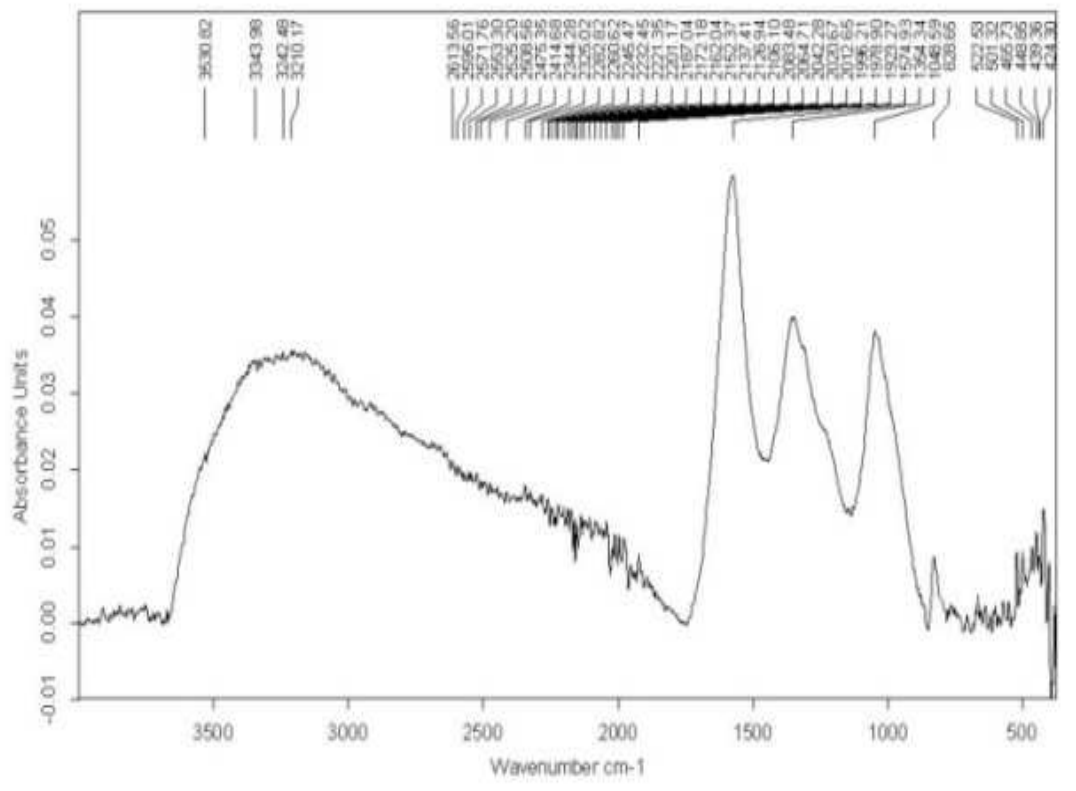

a) $\mathrm{GO}-\mathrm{C}_{60}$

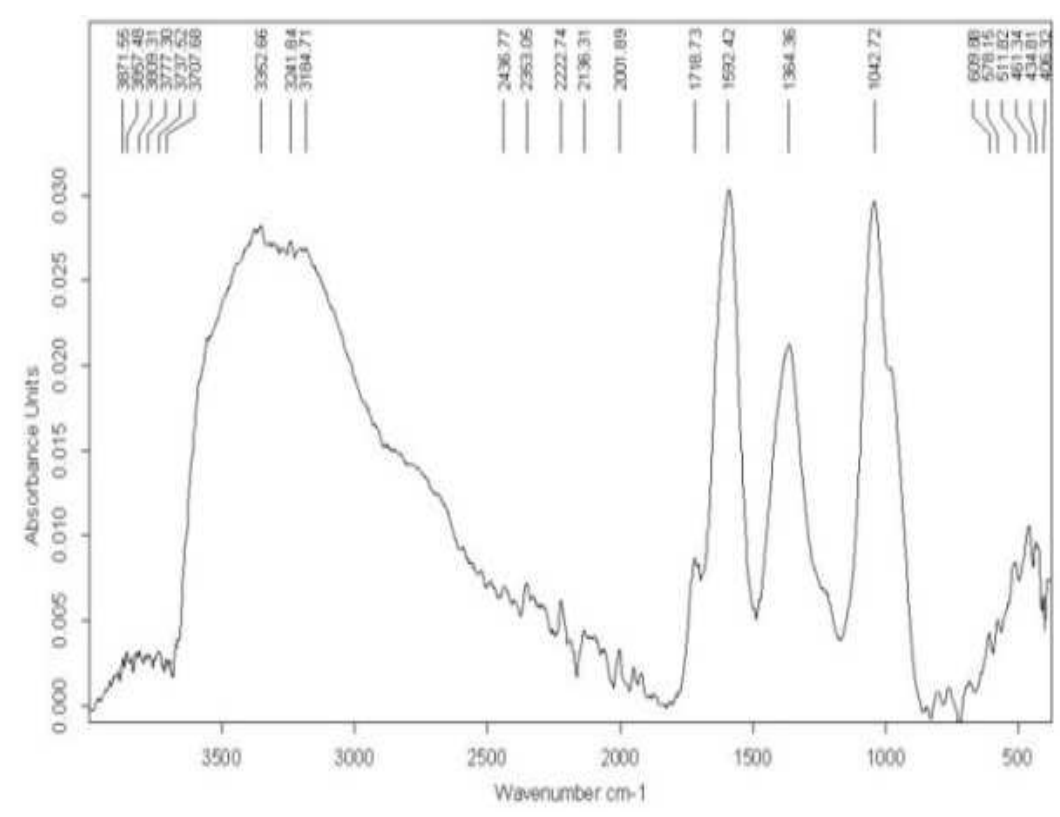

b) $\mathrm{GO}$ 


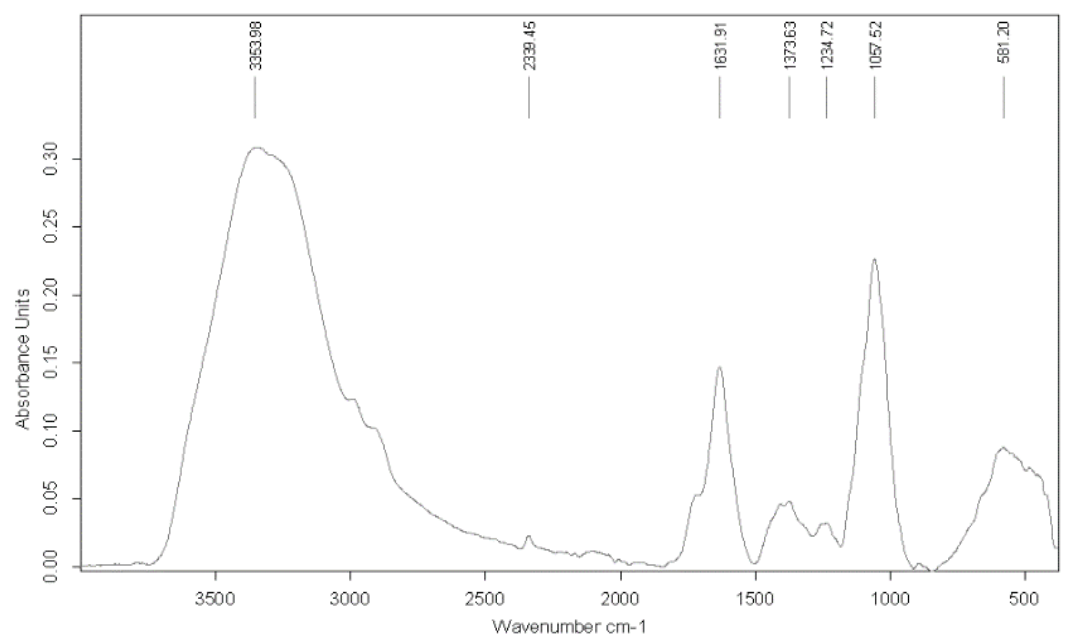

c) cellulose

Fig 15. IR spectrums of products of reaction of $G O-C_{60}(a)$ and $G O(b)$ with cellulose and (c) the initial cellulose alone

For the new products in both cases the IR spectrums did not contain the peaks at $1278 \mathrm{~cm}^{-1}\left(1274 \mathrm{~cm}^{-1}\right)$ and 1228 $\mathrm{cm}^{-1}$ which in the original spectrums GO-C 60 and GO had the assigned vibrations of epoxy groups.

Similar results, i.e. demonstration of deoxidizing (reduction) process, were described for the mutual reaction of GO with heparin (Wang et al., 2012), with a solution of cellulose in 1-butyl-3-methylimidazolium chloride (Peng et al., 2012) and with chitosan - starch (Rodrigues-Gonzales et al., 2012).

\subsection{Thermal Stability of Products of $\mathrm{GO}$ and $\mathrm{GO}_{60}$ Reaction with Cellulose (Nanocellulose)}

TGA curves of samples (see Fig. 16) of composites can be divided into several sections with different slopes, i.e. different weight loss rates. This division, including corresponding temperature intervals and corresponding weight losses, is shown in Tables 4 and 5, which provide parameters of the detected thermal processes on the DSC curve.

For composite samples the DSC curve showed one peak corresponding to an endothermic process and two peaks corresponding to exothermic processes. The second exothermic process was very substantial in both the samples. For the GO- $\mathrm{C}_{60}$-cellulose sample the exothermic process started at $319.8^{\circ} \mathrm{C}$ and the peak area on the DSC curve was $3379.2 \mathrm{~kJ} / \mathrm{kg}$. Equally significant exothermic process in the GO-cellulose sample started at $341.5^{\circ} \mathrm{C}$ and the peak area on the DSC curve was $5261.4 \mathrm{~kJ} / \mathrm{kg}$.

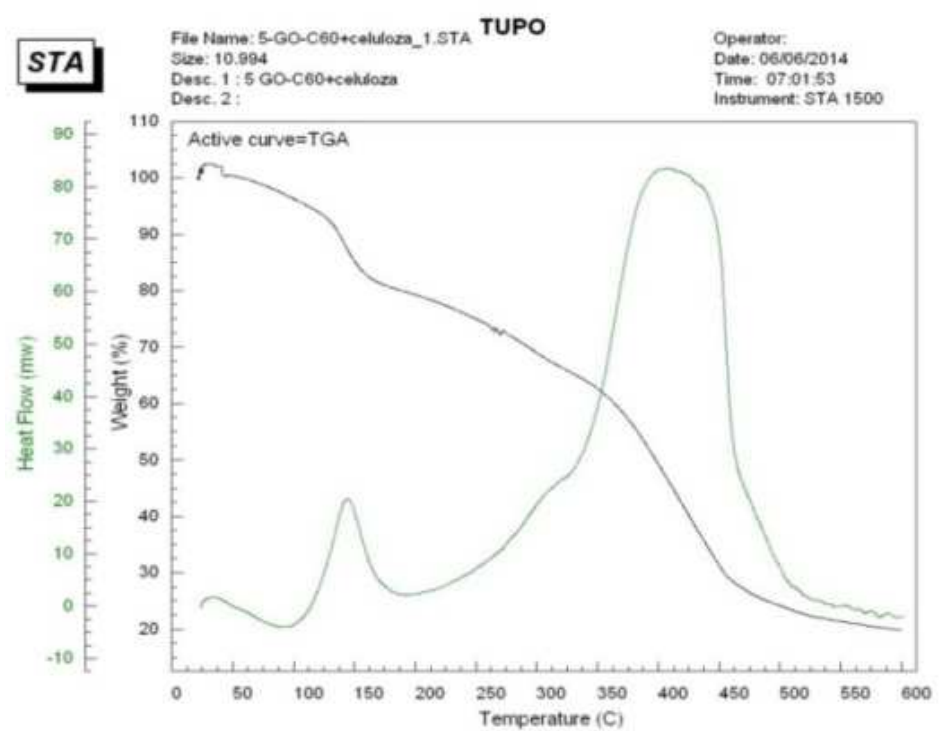

a) GO-C60- cellulose (degradation medium: air, air flow rate $20 \mathrm{ml} / \mathrm{min}$, temperature $25-600^{\circ} \mathrm{C}$, heating rate $10^{\circ} / \mathrm{min}$, sample weight $9.0 \mathrm{mg}$ ) 


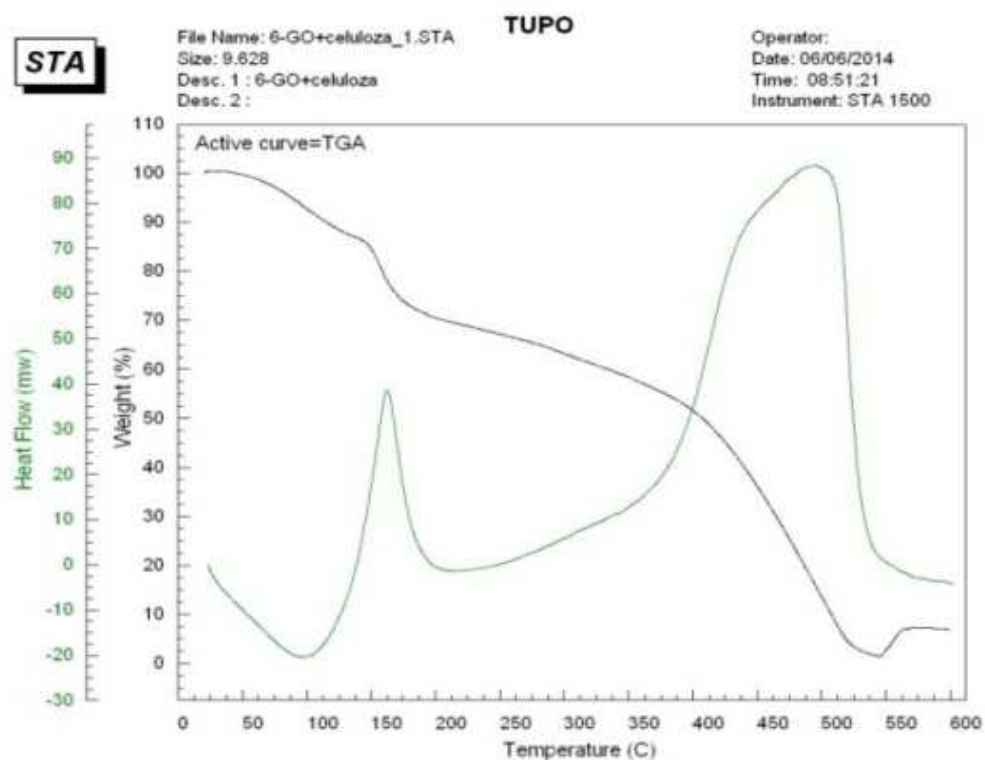

b) $\mathrm{GO}$ - cellulose (degradation medium: air, air flow rate $20 \mathrm{ml} / \mathrm{min}$, temperature $25-600^{\circ} \mathrm{C}$, heating rate $10^{\circ} / \mathrm{min}$, sample weight $9.0 \mathrm{mg}$ )

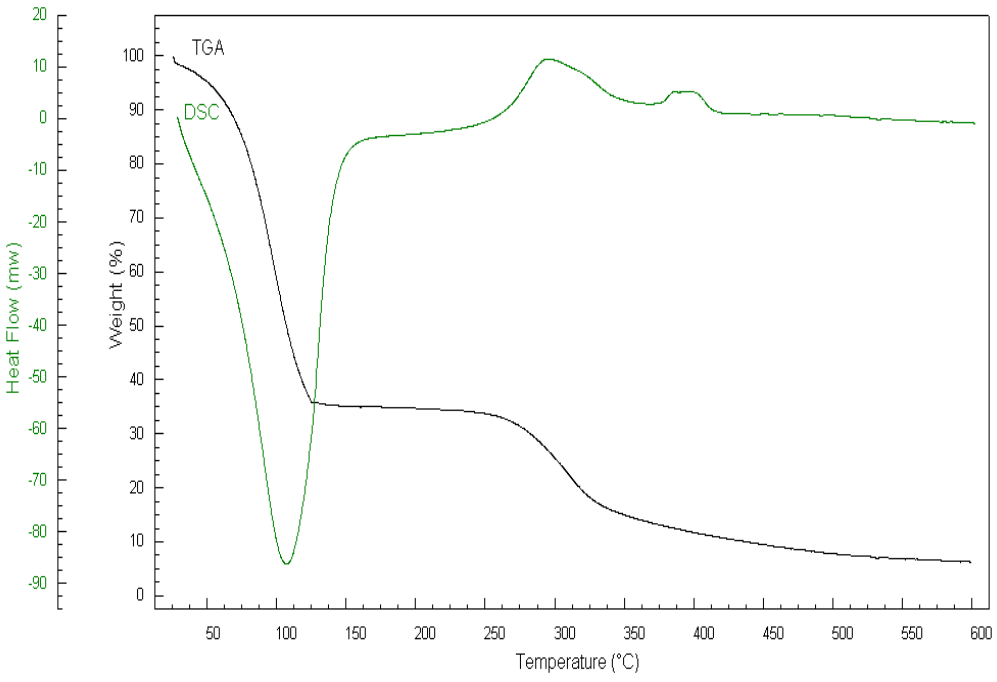

Fig 16. IR spectrum of composites GO-C60-cellulose a), GO-cellulose b), initial cellulose c) (degradation medium: air, air flow rate $20 \mathrm{ml} / \mathrm{min}$, temperature $25-600^{\circ} \mathrm{C}$, heating rate $10 \% \mathrm{~min}$, sample weight $11.79 \mathrm{mg}$ )

Tab 4. Division of TGA curves into temperature intervals

\begin{tabular}{llll}
\hline Sample No. & Interval No. & Temperature range $\left({ }^{\circ} \mathbf{C}\right)$ & Weight loss (\%) \\
\hline & 1 & $25.0-42.4$ & 0.3 \\
GO-C $60-$ cel. & 2 & $42.4-123.9$ & 6.9 \\
& 3 & $123.9-168.9$ & 11.9 \\
& 4 & $168.9-347.8$ & 18.5 \\
& 5 & $347.8-474.3$ & 36.4 \\
& 6 & $474.3-600.0$ & 6.8 \\
& 1 & $25.0-57.3$ & 0.9 \\
GO - cel. & 2 & $57.3-120.8$ & 10.1 \\
& 3 & $120.8-144.6$ & 3.0 \\
& 4 & $144.6-180.6$ & 13.2 \\
& 5 & $180.6-396.5$ & 20.6 \\
cellulose & 6 & $396.5-522.6$ & 48.3 \\
& 7 & $522.6-545.0$ & 2.5 \\
& 1 & $25.0-62.9$ & 8.5 \\
& 2 & $62.9-124.9$ & 55.6 \\
& 3 & $124.9-265.8$ & 3.3 \\
& 4 & $265.8-333.4$ & 15.8 \\
\hline
\end{tabular}


Tab 5. Parameters of the ongoing thermal processes (DSC)

\begin{tabular}{|c|c|c|c|c|c|}
\hline Sample No. & Thermal process No. & Temperature range $\left({ }^{\circ} \mathrm{C}\right)$ & $\Delta \mathrm{H}(\mathrm{kJ} / \mathrm{kg}) *$ & $\mathrm{H}_{\mathrm{fl}}(\mathrm{mW})$ & $\Sigma \Delta H(\mathrm{kj} / \mathrm{kg})$ \\
\hline \multirow{3}{*}{ GO- $\mathrm{C}_{60}-$ cel. } & 1 & $31.6-115.3$ & 159.9 & 5.7 & \multirow{3}{*}{-3470.2} \\
\hline & 2 & $115.3-187.2$ & -251.1 & 18.7 & \\
\hline & 3 & $319.8-531.0$ & -3379.0 & 59.2 & \\
\hline \multirow{3}{*}{ GO - cel. } & 1 & $25.0-133.1$ & 757.5 & 17.7 & \multirow{3}{*}{-5085.1} \\
\hline & 2 & $133.1-208.1$ & -581.2 & 41.7 & \\
\hline & 3 & $341.54-557.2$ & -5261.4 & 76.8 & \\
\hline \multirow{3}{*}{ cellulose } & 1 & $25.0-154.0$ & 3053.7 & 86.2 & \multirow{3}{*}{+2805.7} \\
\hline & 2 & $247.9-344.8$ & -211.3 & 12.2 & \\
\hline & 3 & $372.0-414.6$ & -36.7 & 2.3 & \\
\hline
\end{tabular}

$* \Delta \mathrm{H}=$ thermal effect of the process based on DSC curves

( $\Delta \mathrm{H}>0 \ldots$ endothermic process, $\Delta \mathrm{H}<0 \ldots$ exothermic process)

The comparison of thermal stabilities of the prepared GO and $\mathrm{GO}-\mathrm{C}_{60}$ composites with cellulose indicates that the foil prepared from GO is thermally more stable but its decomposition releases more thermal energy.

A principle difference can be found when we compare thermal stability (weight loss) of the initial foils of GO and GO- $\mathrm{C}_{60}$ and thermal stability of their composites with cellulose. The weight loss in the temperature interval 25$220^{\circ} \mathrm{C}$ was $63 \%$ for $\mathrm{GO}$ foils and $72 \%$ for $\mathrm{GO}-\mathrm{C}_{60}$ foils. For the composites the weight loss was $32 \%$ and $22 \%$ respectively, which means a major difference. A completely different is the thermal decomposition of the initial cellulose. The decomposition in the temperature interval $25-154^{\circ} \mathrm{C}$ is accompanied by an endothermic process with the thermal effect $3053.7 \mathrm{~kJ} / \mathrm{kg}$ and the weight loss of the sample is $64 \%$.

\subsection{GO Reaction with $\beta-1,3-1,6-$ D-Glucan}

Glucans rank among homopolysacharides, they have a long chain with only one structural component - glucose (hexose). Glucose in the chain is attached in the positions
1,3 and 1,6. Smaller chains branch off from the main chain. The structure of glucans is of extraordinary importance in activation of the immunity system where branching of the side chains plays a major role.

$\beta$-D-glucans are indigestible polysaccharides that occur in nature in sources such as cereal grains, yeasts, fungi, bacteria and algae. Biological effects of beta-glucans are manifested at several levels. The main role consists in activation of immunity system cells (macrophage) and they also perform anti-carcinogenic, antimicrobial, antiviral and antialergic activities. Beta-glucans also have a radioprotective effect - they deactivate free radicals (Chovancová and Šturdík, 2005).

We performed reaction of beta-glucan with grapheneoxide under ultrasonification conditions without sulfuric acid and in acid environment.

\subsection{FT-IR Analysis of the Foils (GO-ßG and $\left.\mathrm{GO}-\beta G \mathrm{H}^{+}\right)$}

The obtained spectrums of the products are shown in Fig. 17 from left to right: GO- $\beta \mathrm{G}, \mathrm{GO}-\beta \mathrm{GH}^{+}$and initial $\beta \mathrm{G}$. In the last picture $d$ ) the three spectrums are compared.

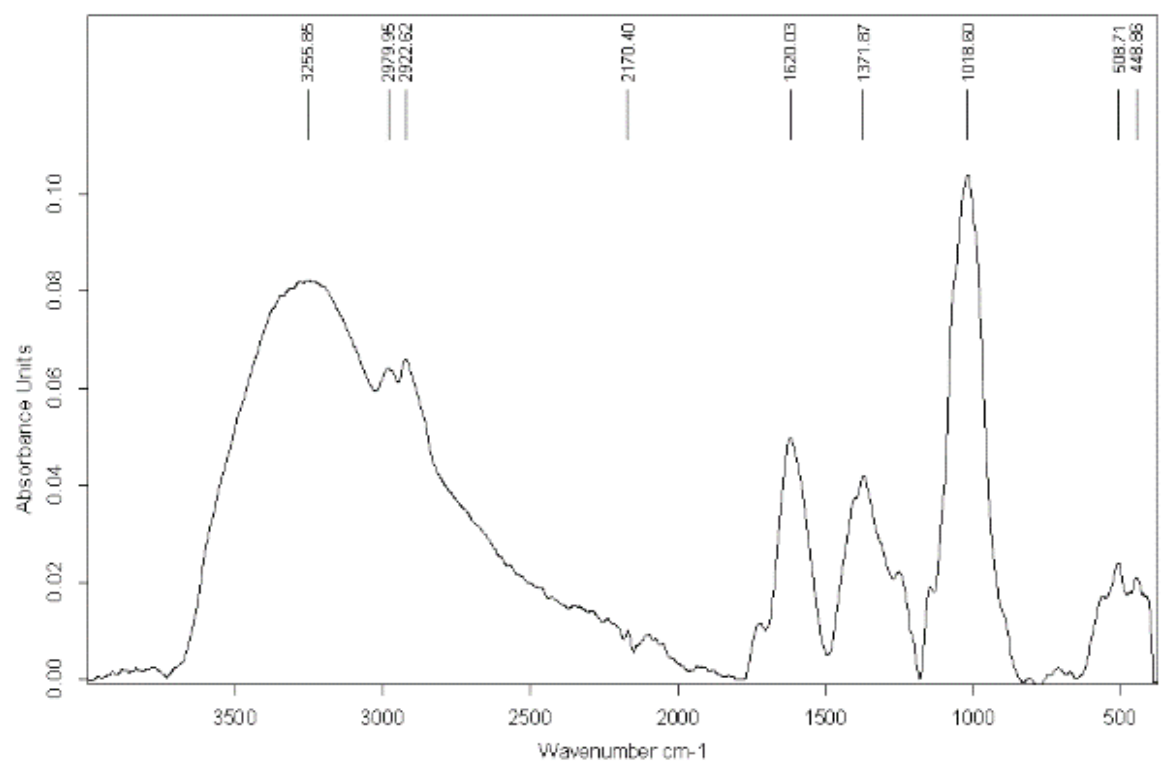

a) $\mathrm{GO}-\beta \mathrm{G}$ 


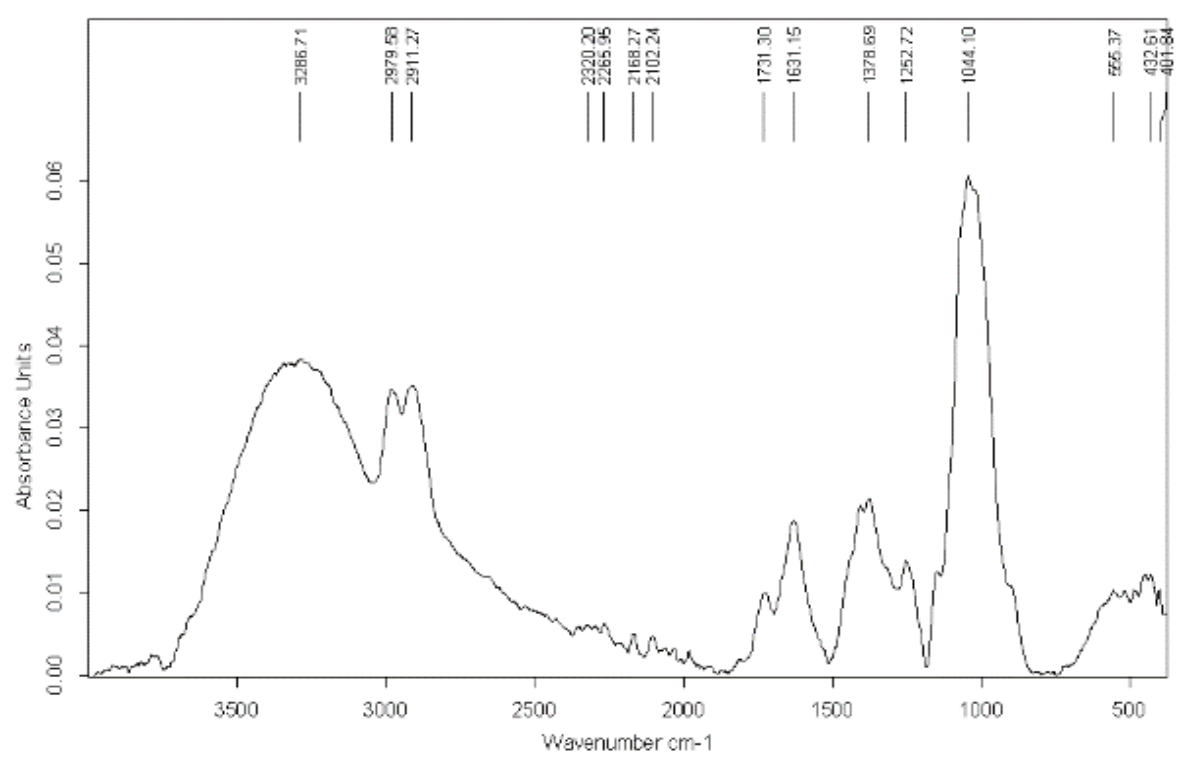

b) $\mathrm{GO}-\mathrm{BGH}^{+}$

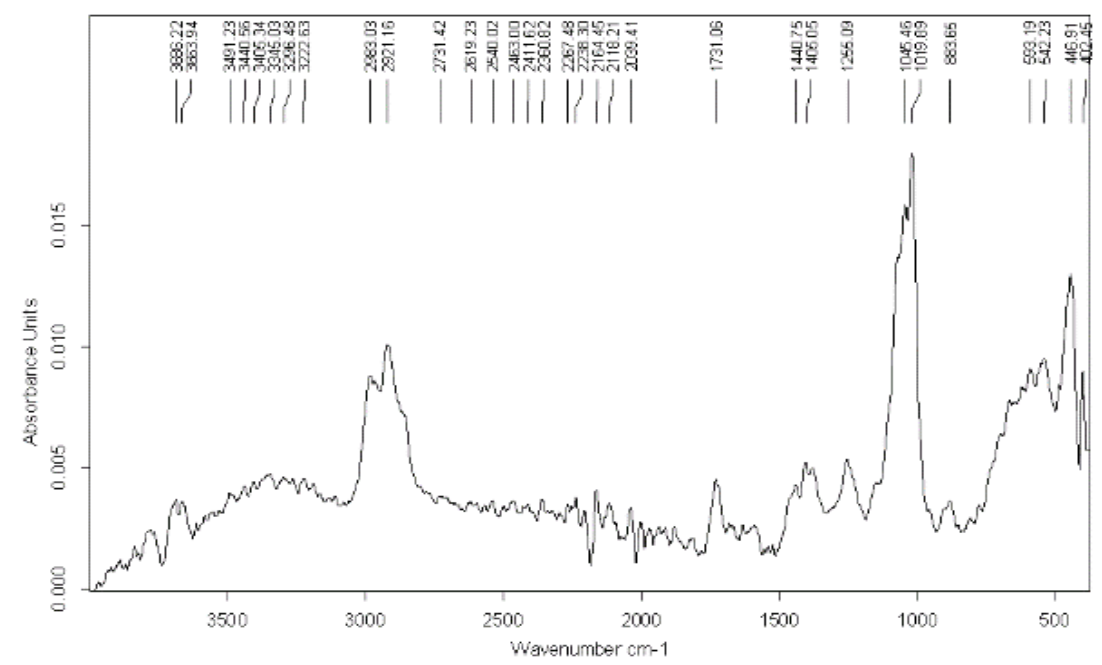

c) $B G$

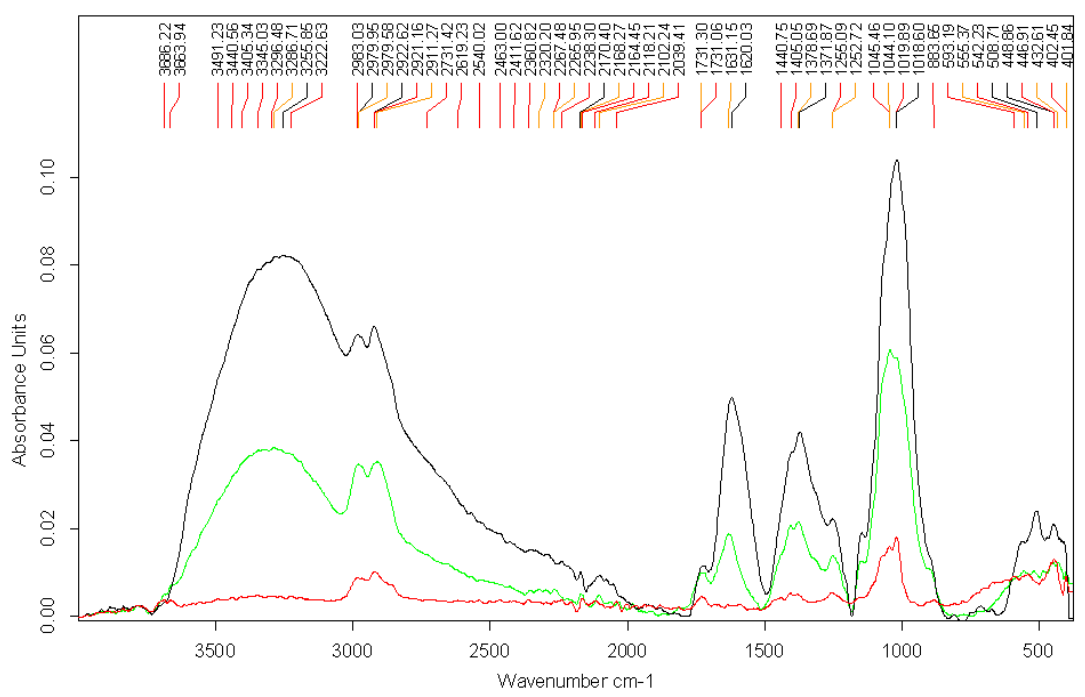

d) Combined spectrums. a) black + b) green + c) red

Fig 17. IR spectrums of the reaction products: a) $\left.G O-\beta G, b) G O-\beta G H^{+}, c\right) \beta G$, d) comparison of the spectrums shown in $a+b+c$ 
At the first sight the IR spectrums shown above are similar but a more detailed inspection of the GO- $\beta \mathrm{G}$ and $\mathrm{GO}-\mathrm{BGH}^{+}$spectrums shows differences in absorbance values, mutual ratio of peak intensity and in shifts of frequencies of decisive bond vibrations, e.g.:

$\begin{array}{lll} & \text { GO- } \beta \mathrm{G} & \mathrm{GO}-\beta \mathrm{GH}^{+} \\ \mathrm{C}-\mathrm{O}-\mathrm{C} & 1018 \mathrm{~cm}^{-1} & 1044 \mathrm{~cm}^{-1} \\ -\mathrm{OH} & 3255 \mathrm{~cm}^{-1} & 3286 \mathrm{~cm}^{-1} \\ -\mathrm{C}=\mathrm{C}- & 1620 \mathrm{~cm}^{-1} & 1631 \mathrm{~cm}^{-1}\end{array}$

The values of the initial GO are: C-O-C $1068 \mathrm{~cm}^{-1}, 9.79$ $\mathrm{cm}^{-1}$, $-\mathrm{OH} 3149-3186 \mathrm{~cm}^{-1},-\mathrm{C}=\mathrm{C}-1613 \mathrm{~cm}^{-1}$.

\subsection{Thermal Stability of the Product (GO- $\left.\beta G, G O-\beta G H^{+}\right)$ and Initial $\beta G$}

The measured results in a graphic form are provided in Fig. 18-20 and interpretation of the TGA and DSC curves is provided in Tables 6-7. The DSC curve of $B G$ features one peak corresponding to an endothermic thermal process with minimum weight loss and prominent, partly overlapping peaks that correspond to exothermic thermal processes which start at $257^{\circ} \mathrm{C}$ and are accompanied by a significant loss of the sample weight.

A common characteristic of both the prepared composite products is that their weight loss curves (TGA) can be approximated with a line - continuous linear reduction of weight, unlike the step weight loss in case of $\beta G$ which was up to $70 \%$ (see Fig. 18) and in case of GO up to $60 \%$ (see Fig. 5). The products differ from each other by the number of exothermic effects and the shift of the last exothermic effect by $42^{\circ} \mathrm{C}$ in favor of $\mathrm{GO}-3 \mathrm{GH}^{+}$.

The overall thermal effect in the course of decomposition decreases from the initial $\beta \mathrm{G}$ to the $\mathrm{GO}-\beta \mathrm{GH}^{+}$composite (see Tab. 2).

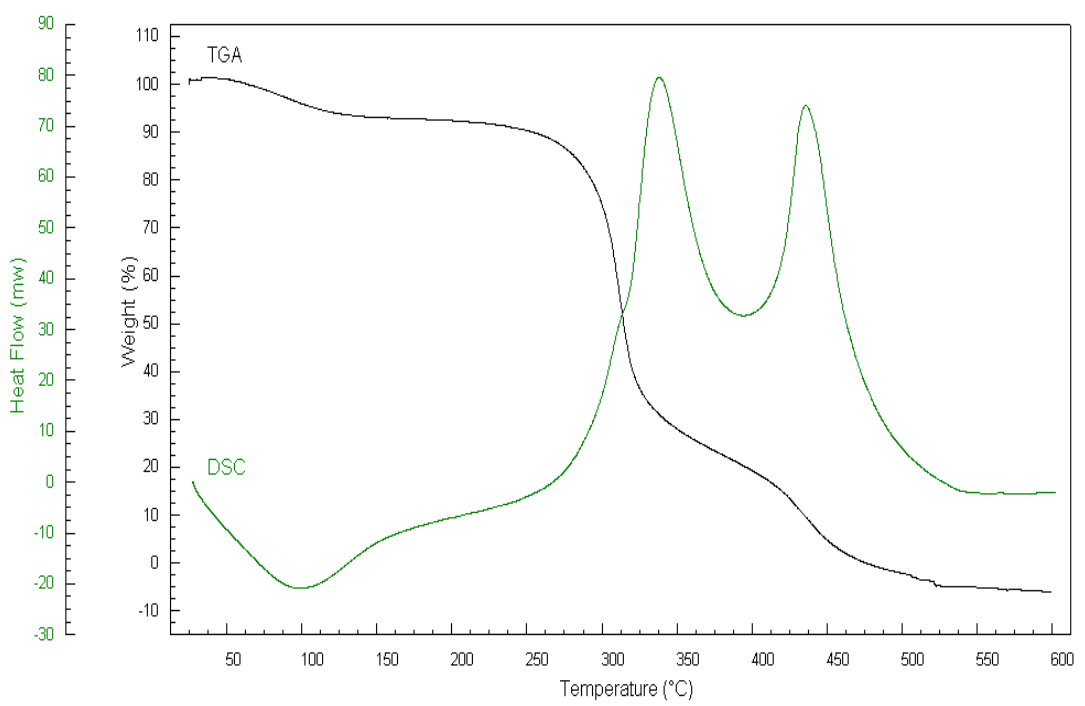

Fig 18. Thermal analysis of $\beta G$ (degradation medium: air, air flow rate $20 \mathrm{ml} / \mathrm{min}$, temperature $25-600^{\circ} \mathrm{C}$, heating rate $10^{\circ} / \mathrm{min}$, sample weight $11.03 \mathrm{mg}$ ).

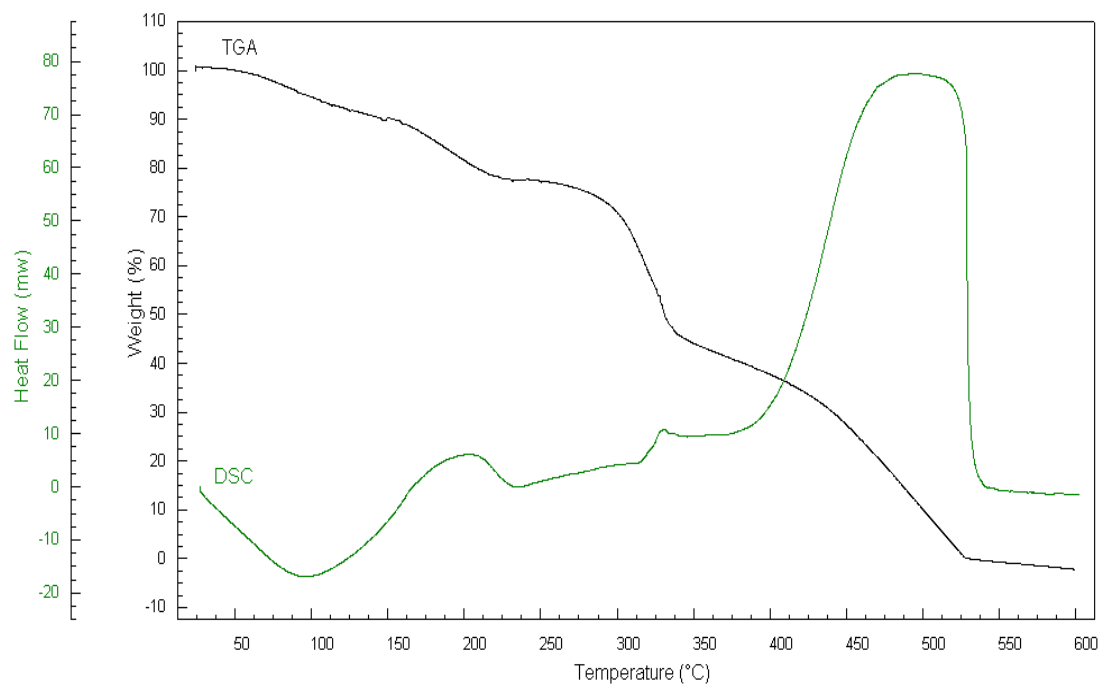

Fig 19. Thermal analysis of GO- $\beta$ G (degradation medium: air, air flow rate $20 \mathrm{ml} / \mathrm{min}$, temperature $25-600^{\circ} \mathrm{C}$, heating rate $10^{\circ} / \mathrm{min}$, sample weight 11.47 $m g)$. 


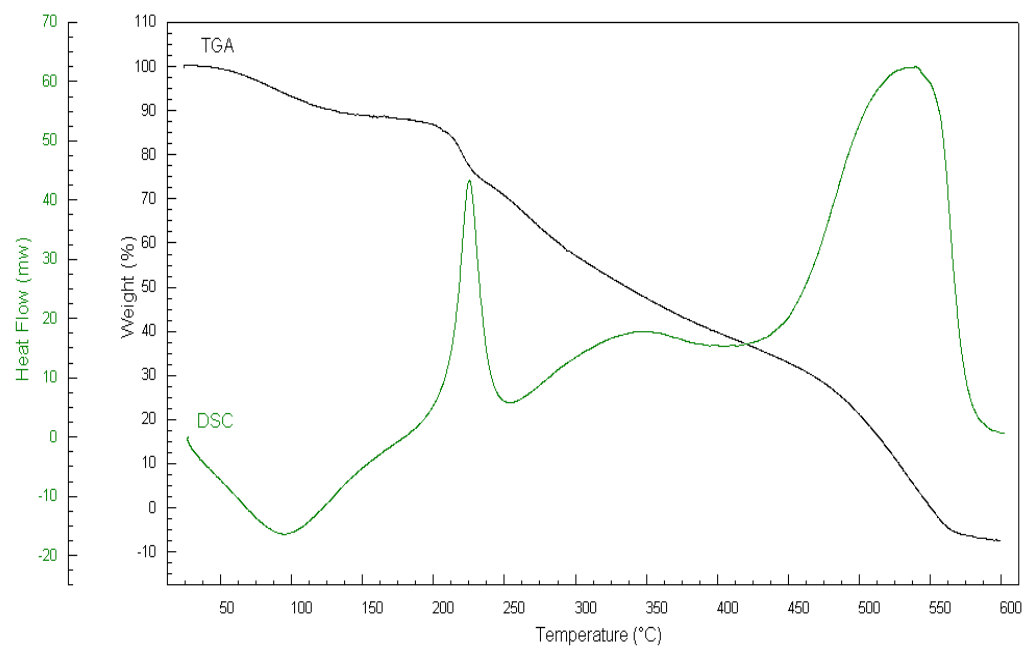

Fig 20. Thermal analysis of GO- $\beta G H+\left(\right.$ degradation medium: air, air flow rate $20 \mathrm{ml} / \mathrm{min}$, temperature $25-600^{\circ} \mathrm{C}$, heating rate $10^{\circ} / \mathrm{min}$, sample weight $10.77 \mathrm{mg}$ ).

Tab 6. Division of the TGA curves into temperature intervals ${ }^{x}$

\begin{tabular}{llll}
\hline Sample No. & Interval No. & Temperature range $\left({ }^{\circ} \mathbf{C}\right)$ & Weight loss(\%) \\
\hline & 1 & $25.0-114.4$ & 5.5 \\
& 2 & $114.4-278.1$ & 8.6 \\
BG & 3 & $278.1-330.3$ & 52.2 \\
& 4 & $330.3-412.7$ & 17.0 \\
& 5 & $412.7-462.4$ & 14.8 \\
& 6 & $462.4-475.9$ & 14.8 \\
& 1 & $25.0-149.4$ & 9.9 \\
GO- $\beta \mathrm{G}$ & 2 & $149.4-225.5$ & 12.3 \\
& 3 & $225.5-292.3$ & 4.7 \\
& 4 & $292.3-337.9$ & 26.7 \\
& 5 & $337.9-438.4$ & 15.7 \\
& 6 & $438.4-529.8$ & 30.7 \\
$\mathrm{GO}-\beta \mathrm{GH}^{+}$ & 1 & $25.0-124.2$ & 9.9 \\
& 2 & $124.2-204.2$ & 4.2 \\
& 3 & $204.2-230.8$ & 10.9 \\
& 4 & $230.8-321.6$ & 22.5 \\
& 5 & $321.6-480.9$ & 25.9 \\
\hline
\end{tabular}

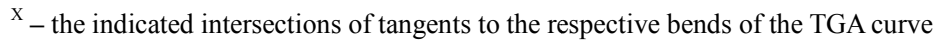

Tab 7. Parameters of the thermal processes (DSC)

\begin{tabular}{|c|c|c|c|c|c|}
\hline Sample No. & Thermal process No. & Temperature range $\left({ }^{\circ} \mathrm{C}\right)$ & $\Delta \mathrm{H}(\mathrm{kJ} / \mathrm{kg}) *$ & $\mathbf{H}_{\mathrm{f} 1}(\mathbf{m W})$ & $\Sigma \Delta H(\mathbf{k j} / \mathbf{k g})$ \\
\hline \multirow{2}{*}{ BG } & 1 & $25.0-153.9$ & 805.9 & 21.3 & \multirow{3}{*}{-3586.6} \\
\hline & 2 & $257.5-528.4$ & -4392.5 & 81.0 & \\
\hline \multirow{4}{*}{ GO- $ß \mathrm{G}$} & 1 & $25.0-157.0$ & 825.3 & 16.9 & \\
\hline & 2 & $157.0-228.8$ & -147.1 & 8.9 & \multirow[t]{3}{*}{-2734.9} \\
\hline & 3 & $311.0-356.5$ & -36.3 & 6.2 & \\
\hline & 4 & $383.3-539.3$ & -3376.8 & 66.4 & \\
\hline \multirow{3}{*}{$\mathrm{GO}-\beta_{\mathrm{GH}^{+}}$} & 1 & $25.0-145.9$ & 685.2 & 16.7 & \multirow{3}{*}{-2084.7} \\
\hline & 2 & $197.2-250.0$ & -313.5 & 38.2 & \\
\hline & 3 & $425.4-589.3$ & -2456.4 & 46.2 & \\
\hline
\end{tabular}

$\Delta \mathrm{H}=$ thermal effect of the process based on DSC curves $(\Delta \mathrm{H}>0 \ldots$ endothermic process, $\Delta \mathrm{H}<0$. exothermic process $)$

$\mathrm{H}_{\mathrm{fl}}=$ height of the peak of a thermal process on the DSC curve in an absolute value related to the point corresponding to the beginning of the thermal process

\section{Conclusion}

Joint oxidation of graphite and fullerene $\mathrm{C}_{60}$ in the ratio 2:1 makes it possible to prepare a compound in form of compact foils but it has a lower thermal stability and its thermal decomposition is accompanied by thermal effects that are $30 \%$ bigger than effects produced by foils without fullerene. A method of attachment between oxidized graphite and fullerene has not been demonstrated. The prepared foil can also have other chemical and 
physicochemical properties thanks to the fullerene molecule (Troshin et al., 2008).

Thermal decomposition of composites of GO and GO$\mathrm{C}_{60}$ with nanocellulose is accompanied by bigger thermal effects than the effects produced by the initial GO and $\mathrm{GOC}_{60}$ foils. The same applies also for $\beta$-glucan in respect to GO. However, the thermal effect of the decomposition is lower than for B-glucan alone.

The products we prepared were in the form of foils (membranes), with the exception of the "blank test" of fullerene oxidation. GO-foils (papers) are prepared by vacuum filtration of $\mathrm{GO}$ dispersion. This is the basic method of its preparation which we have also applied. We are fully aware of the fact that mechanical, electronic, chemical and biological properties and the related toxicological properties are affected by many factors which may have influenced our results of thermal stability measurements. The first factor is the method of GO preparation and thus the resulting ratio of $\mathrm{C} / \mathrm{O}$ and topology of the C-skeleton (its defects). The composition of the liquid phase and the concentration (Park et al., 2012) of the filtered suspension influence the foil thickness, as well as the filtration rate, and if the suspension is ultrasonificated then also its duration, temperature and power of the device play a role (Liao et al., 2011). Properties of foils are also influenced by some specific treatments, such as washing of foils with solution of $\mathrm{MCl}_{2}(\mathrm{Ca}, \mathrm{Ba}, \mathrm{Mg})$, while the carbon layers are connected in a plane, across via dialdehyde $\mathrm{Hu}$ et al., 2011), or its impregnation e.g. with $\mathrm{Ti}, \mathrm{Ag}, \mathrm{Cu}_{2} \mathrm{O}$ (Chen et. al., 2011), expansion of the interlayer space ( $\mathrm{Zhu}$ et al., 2012) etc.

\section{References}

[1] Bondeson, D., Mathew, A., Oksman, K., 2006. Optimization of the isolation of nanocrystals from microcrystalline cellulose by acid hydrolysis. Cellulose, 13, 171-180.

[2] Dreyer, D.R., Park, S., Bielawski, Ch.W. and Ruoff, R.S., 2010. The chemistry of graphene oxide. Chemical Society Reviews, 19, 228-240.

[3] Fakhri, A., 2013. Adsorption characteristics of graphene oxide as a solid adsorbent for aniline removal from aqueous solutions: Kinetics, thermodynamics and mechanism studies. Journal of Saudi Chemical Society.

[4] Faye, O., 2012. Adatom Adsorfbionan Graphene Saeet a First - Principle Study. The African Review of Physics, 7, 315.

[5] Hummers, W.S., Offeman, R.E., 1958. Preparation of Graphitic Oxide. J. Am. Chem. Soc., 80 (6), 1339.

[6] Chabot, V., Higgins, D., Yu, A., Xiao, X., Chen, Z. and Zhang, J., 2014. A review of graphene and graphene oxide sponge: material synthesis and applications to energy and the environment. Energy Environ. Sci., 7, 1564-1596.

[7] Chng, E.L.K., Pumera, M., 2013. The Toxicity of Graphene Oxides, Dependence on the Oxideline Methods. Chem. Eur. $J ., 19$
[8] Chovancová, A., Šturdík, E., 2005. Vliv beta glukánov na imunitní systém člověka (Effects of beta glucans in human immunity system). Nova Biotechnologica, V-I, 105-121.

[9] Ioelovich, M., 2012. Optimal Conditions for Isolation of Nanocrystalline Cellulose Particles. Nanoscience and Nanotechnology, 2 (2), 9-13.

[10] Klouda, K., 1985. Interkalární sloučeniny grafitu. (Intercalation compounds of graphite) Dissertation, VŠCHT Praha (available in the technical library in Prague 6 Dejvice).

[11] Krishnan, D., Kim, F., Luo, J., Cruz-Silva, R., Cote, L.J., Jang, H., Huang, J., 2012. Energetic Graphene oxide: Challenges and opportunities. Nanotoday, 7, 137-152.

[12] Kyzas, G. Z., Deliyanni, E. A. and Matis, K. A., 2014. Graphene oxide and its application as an adsorbent for wastewater treatment. J. Chem. Technol. Biotechnol., 89, 196-205.

[13] Li, Y. and Ragauskas, A. J., 2011. Cellulose Nano Whiskers as a Reinforcing Filler in Polyurethanes. Advances in Diverse Industrial Applications of Nanocomposites, Dr. Boreddy Reddy (Ed.).

[14] Makharza, S., Cirillo, G., Bachmatiuk, A., Ibrahim, I., Ioannides, N., Trzebicka, B., Hampel, S., Rümmeli, M.H., 2013. Graphene oxide-based drug delivery vehicles: functionalization, characterization, and cytotoxicity evaluation. Journal of Nanopart Res, 15, 2099.

[15] Neto, A.H.C., 2009. Adatoms in Graphene. Solid State Communications, 149, 1094-1100.

[16] Peng, B. L., Dhar, N., Liu, H. L. and Tam, K. C., 2011. Chemistry and Applications of Nanocrystalline Cellulose and its Derivatives: A nanotechnology Perspective. The Canadian Journal of Chemical Engineering, 9999.

[17] Peng, H., Meng, L., Niu, L. and Lu, Q., 2012. Simultaneous Reduction and Surface Functionalization of Graphene Oxide by Natural Cellulose with the Assistance of the Ionic Liquid. The Journal of Physical Chemistry, 116, 1629416299.

[18] Rodrígues-González, C., Martínez-Hernández, A.L., Castano V., Kharissova, O.V., Ruoff, R.S. and VelascoSantos, C., 2012. Polysaccharide Nanocomposites Reinforced with Graphene Oxide and Keratin-Grafted Graphene Oxide. Industrial \& Engineering Chemistry Research, 51, 3619-3629.

[19] Russo, P., Hu, A., Compagnini, G., 2013. Synthesis, Properties and Potential Applications of Porous Graphene: A Review. Nano-microletters, 5(4), 260-273.

[20] Shen, H., Zhang, L., Liu, M., Zhang, Z., 2012. Biomedical Applications of Graphene. Theranostics, 2(3), 283-294.

[21] Troshin, P.A., Lyubovskaya, R.N., 2008. Organic chemistry of fullerenes: the major reactions, types of fullerene derivatives and prospects for their practical use. Russian Chemical Reviews, 77(4), 305-349.

[22] Trzaskowski, B., Adamowicz, L., Beck, W., Muralidharan, K., 2013. Impact of Local Curvature and Structural Defects on Graphene- $\mathrm{C}_{60}$ Fullerene Fusion Reaction. BBarriers $J$. Phys. Chem., 19669-19671. 
[23] Wang, Y., Zhang, P., Lie, Ch. F., Zhan, Y., Li, Y. F. and Huang, Ch. Z., 2012. Green and easy synthesis of biocompatible graphene for use as an anticoagulant. The Royal Society of Chemistry, 2, 2322-2328.

[24] Yoo, B.M., Shin, H.J., Yoon, H.W., Park, H.B., 2013. Graphene and graphene oxide and their uses in barrier polymers. Journal of Polymer Science: Polymer Physics.

[25] Zhang, Y., Ren, L., Wang, S., Marathe, A., Chaudhuri, J. and Li, G., 2011. Functionalization of graphene sheets through fullerene attachment. Journal of Materials Chemistry, 21,5386 .

[26] Liao, K-H., Lin, Y-S., Macosko, Ch.W. and Haynes Ch.L., 2011. Cytotoxicity of Graphene Oxide and Graphene in Human Erythrocytes and Skin Fibroblasts. ACS Appl. Mater. Interfaces, 3, 2607-2615.

[27] Zhu, J., Zhu, L., Lu, Z., Gu, L., Cao, S. and Cao, X., 2012. Selectively Expanding Graphene Oxide Paper for Creating Multifunctional Carbon Materials. J. Phys. Chem. C, 116 (43), 23075-23082.

[28] Park, S., Suk, J.W., An, J., Oh, J., Lee, S., Lee, W., Potts, J.R., Byun, J-H. and Ruoff, R.S., 2012. The effect of concentration of graphene nanoplatelets on mechanical and electrical properties of reduced graphene oxide papers. Carbon, 50, 4573-4578.
[29] Chen, J., Zhang, G., Luo, B., Sun, D., Yan, X. and Xue, Q., 2011. Surface amorphization and deoxygenation of graphene oxide paper by $\mathrm{Ti}$ ion implantation. Carbon, 49, 3141-3147.

[30] Hu, N., Meng, L., Gao, R., Wang, Y., Chai, J., Yang, Z., Kong, E.S-W. and Zhang, Y., 2011. A Facile Route for the Large Scale Fabrication of Graphene Oxide Papers and Their Mechanical Enhancement by Cross-linking with Glutaraldehyde. Nano-MicroLetters, 3 (4), 215-222.

[31] Su, Ch. and Loh, K.P., 2013. Carbocatalysts: Graphene Oxide and Its Derivatives. Acc. Chem. Res., 46 (10), 2275 2285.

[32] Navalon, S., Dhakshinamoorthy, A., Alvaro, M. and Garcia, H., 2014. Carbocatalysis by Graphene-Based Materials. Chem. Rev., 114 (12), 6179-6212.

[33] Saeedfar, K., Heng, L.Y., Ling, T.L. and Rezayi, M., 2013. Potentiometric Urea Biosensor Based on an Immobilised Fullerene-Urease Bio-Conjugate. Sensors (Basel), 13 (12), 16851-16866.

[34] Kabir, M., Mukherjee, S. and Saha-Dasgupta, T., 2011. Substantial reduction of Stone-Wales activation barrier in fullerene. Physical Review 